\title{
Global gap-analysis of amphipod barcode library
}

\author{
Anna Maria Jażdżewska ${ }^{\text {Corresp., } 1}$, Anne Helene S. Tandberg ${ }^{2}$, Tammy Horton $^{3}$, Saskia Brix ${ }^{4}$ \\ ${ }^{1}$ Department of Invertebrate Zoology and Hydrobiology, Faculty of Biology and Environmental Protection, University of Lodz, Lodz, Poland \\ 2 University Museum, Department of Natural History, University of Bergen, Bergen, Norway \\ 3 National Oceanography Centre, Southampton, United Kingdom \\ 4 Department for Marine Biodiversity Research (DZMB), Senckenberg am Meer, Hamburg, Germany \\ Corresponding Author: Anna Maria Jażdżewska \\ Email address: anna.jazdzewska@biol.uni.lodz.pl
}

In the age of global climate change and biodiversity loss there is an urgent need to provide effective and robust tools for diversity monitoring. One of the promising techniques for species identification is the use of DNA barcoding that in Metazoa utilizes the so called 'gold-standard' gene of cytochrome $c$ oxidase (COI). However, the success of this method relies on the existence of trustworthy barcode libraries of the species. The Barcode of Life Data System (BOLD) aims to provide barcodes for all existing organisms, and is complemented by the Barcode Index Number (BIN) system serving as a tool for potential species recognition. Here we provide an analysis of all public COI sequences available in BOLD of the diverse and ubiquitous crustacean order Amphipoda, to identify the barcode library gaps and provide recommendations for future barcoding studies. Our gap analysis of 25702 records has shown that although 3835 BINs (indicating putative species) were recognised by BOLD, only $10 \%$ of known amphipod species are represented by barcodes. We have identified almost equal contribution of both records (sequences) and BINs associated with freshwater and with marine realms. Three quarters of records have a complete species-level identification provided, while BINs have just $50 \%$. Large disproportions between identification levels of BINs coming from freshwaters and the marine environment were observed, with three quarters of the former possessing a species name, and less than $40 \%$ for the latter. Moreover, the majority of BINs are represented by a very low number of sequences rendering them unreliable according to the quality control system. The geographical coverage is poor with vast areas of Africa, South America and the open ocean acting as "white gaps". Several, of the most species rich and highly abundant families of Amphipoda (e.g. Phoxocephalidae, Ampeliscidae, Caprellidae), have very poor representation in the BOLD barcode library. As a result of our study we recommend stronger effort in identification of already recognised BINs, prioritising the studies of families that are known to be important and abundant 
components of particular communities, and targeted sampling programs for taxa coming from geographical regions with the least knowledge. 


\section{Global gap-analysis of amphipod barcode library}

\section{Anna M. Jażdżewska1, Anne Helene S. Tandberg ${ }^{2}$, Tammy Horton ${ }^{3}$, Saskia Brix ${ }^{4}$}

$3{ }^{1}$ Department of Invertebrate Zoology and Hydrobiology, Faculty of Biology and Environmental

4 Protection, University of Lodz, Lodz, Poland, author ORCID: 0000-0003-2529-0641

$5{ }^{2}$ University of Bergen, University Museum, Department of Natural History, Bergen, Norway, 6 author ORCID: 0000-0003-3470-587X

$7 \quad{ }^{3}$ National Oceanography Centre, Southampton, UK, author ORCID: 0000-0003-4250-1068

$8{ }^{4}$ Senckenberg am Meer, Department for Marine Biodiversity Research (DZMB), Hamburg, 9 Germany, author ORCID: 0000-0002-3269-8904

10 Corresponding Author:

11 Anna Jażdżewska ${ }^{1}$

12 12/16 Banacha st., 90-237 Lodz, Poland

13 Email address: anna.jazdzewska@biol.uni.lodz.pl

\section{Abstract}

In the age of global climate change and biodiversity loss there is an urgent need to provide effective and robust tools for diversity monitoring. One of the promising techniques for species identification is the use of DNA barcoding that in Metazoa utilizes the so called 'gold-standard' gene of cytochrome $c$ oxidase (COI). However, the success of this method relies on the existence of trustworthy barcode libraries of the species. The Barcode of Life Data System (BOLD) aims to provide barcodes for all existing organisms, and is complemented by the Barcode Index Number (BIN) system serving as a tool for potential species recognition. Here we provide an analysis of all public COI sequences available in BOLD of the diverse and ubiquitous crustacean order Amphipoda, to identify the barcode library gaps and provide recommendations for future barcoding studies. Our gap analysis of 25702 records has shown that although 3835 BINs 
26 (indicating putative species) were recognised by BOLD, only $10 \%$ of known amphipod species

27 are represented by barcodes. We have identified almost equal contribution of both records

28 (sequences) and BINs associated with freshwater and with marine realms. Three quarters of

29 records have a complete species-level identification provided, while BINs have just 50\%. Large

30 disproportions between identification levels of BINs coming from freshwaters and the marine

31 environment were observed, with three quarters of the former possessing a species name, and

32 less than $40 \%$ for the latter. Moreover, the majority of BINs are represented by a very low

33 number of sequences rendering them unreliable according to the quality control system. The

34 geographical coverage is poor with vast areas of Africa, South America and the open ocean

35 acting as "white gaps". Several, of the most species rich and highly abundant families of

36 Amphipoda (e.g. Phoxocephalidae, Ampeliscidae, Caprellidae), have very poor representation in

37 the BOLD barcode library. As a result of our study we recommend stronger effort in

38 identification of already recognised BINs, prioritising the studies of families that are known to be

39 important and abundant components of particular communities, and targeted sampling programs

40 for taxa coming from geographical regions with the least knowledge.

42 Keywords

43 DNA barcoding, Crustacea, marine, freshwater, semi-terrestrial, taxonomic identification

\section{Introduction}

46 Nature in the age of Anthropocene is facing numerous global changes and challenges. One of the

47 drastic results of human associated activities is the acceleration of species extinctions, with one 
48 million species estimated to be presently critically endangered (IPBES, 2019). What is more,

49 although the rate of species discovery grows, large numbers of species remain undescribed and it

50 is believed many will not be recognized before they go extinct (Mora et al., 2011, Brix et al.

51 2020). This raises the challenge of efficient environmental monitoring, which is crucial for

52 biodiversity recognition and preservation. Monitoring based on the taxonomic identification of

53 organisms in samples is time-consuming and requires knowledge of the studied group. In the

54 time of the taxonomic impediment (Ebach, Valdecasas \& Wheeler, 2011), species identification

55 methods offering an alternative to morphology-based methods are of great interest. Utilization of

56 DNA-barcoding (identifying sequences of individual specimens), metabarcoding (high-

57 throughput identification of bulk samples) and the use of environmental DNA (e-DNA,

58 identifying DNA of taxa directly from water or soil sample, without collection of specimens)

59 have been presented as promising methods in monitoring and ecological studies (e.g., Hajibabaei

60 et al., 2012; Cristescu, 2014; Aylagas et al., 2018; Leese et al., 2018; Bush et al., 2019; Feio et

61 al., 2020). The use of metabarcoding in assessing the status of ecosystems has already received

62 the new term "Biomonitoring 2.0" (Bush et al., 2019). Such approaches require the existence of

63 well-established barcode fragment libraries, which allow accurate recognition of organisms in

64 the environment (Cristescu, 2014; Cowart et al., 2015; Oliveira et al., 2016; Múrria et al., 2020).

65 Recent studies indicate that although the use of barcoding in biomonitoring has great advantages

66 over morphological identification, the current gaps in barcode libraries may hinder their use

67 (Weigand et al., 2019; Duarte, Vieira \& Costa, 2020; Feio et al., 2020; Hestetun et al., 2020;

68 Leite et al., 2020; Múrria et al., 2020; Vieira et al. 2021).

69 There are two main repositories where DNA sequences are deposited: NCBI GenBank

70 (www.ncbi.nlm.nih.gov/genbank/, Sayers et al., 2020) and Barcode of Life Data System (BOLD, 
71 www.boldsystems.org, Ratnasingham \& Hebert, 2007). In contrast to GenBank, which

72 assembles nucleotide data of all genes, the primary aim of BOLD is to store data used for species

73 barcoding, which in the case of Metazoa is the cytochrome $c$ oxidase (COI) gene. The

74 development of the BOLD database included the Barcode Index Number (BIN) system

75 implementation (Ratnasingham \& Hebert, 2013) that intends to help in biodiversity assessments

76 by providing species-level taxonomic registry. Based on a molecular species delimitation

77 method, each Molecular Operational Taxonomic Unit (MOTU) recognized by BOLD receives a

78 unique alphanumeric code (BIN). Ideally, each BIN is associated with an accurate taxonomic

79 (preferably species) identification and links to the voucher stored in a recognised institution.

80 However, in practice this is not working well, and at the time of system implementation as many

81 as $46 \%$ of BINs lacked species names (Ratnasingham \& Hebert, 2013). This issue has arisen for

82 a variety of reasons, which we investigate in this study using a particular faunal group, the

83 Amphipoda, as a model.

84 The Order Amphipoda are peracarid crustaceans belonging to the class Malacostraca. They are

85 very diverse components of aquatic environments. According to the World Amphipoda Database

86 (WAD, Horton et al., 2020, accessed on 17-07-2020) there are 10235 accepted amphipod

87 species, the majority of which (78\%) inhabit the marine realm, around $20 \%$ are freshwater

88 species and just 2\% are terrestrial taxa (Horton et al., 2020; Väinölä et al., 2008). The discovery

89 rate of new species has grown steadily since the first amphipod species description and has

90 particularly accelerated in the last six decades (Horton et al., 2020) with mean number of over

91100 taxa annually described since the 1960s (Coleman, 2015). If the trend from the last sixty

92 years persists, we may expect to have ca. 8000 new species described by 2100 . More

93 conservative estimates predict that 6100 new species will be described by that date (Arfianti, 
94 Wilson \& Costello, 2018). The use of molecular methods in the studies of Amphipoda has

95 revealed very high species diversity (e.g. Knox et al., 2012; Verheye, Backeljau \& d'Udekem

96 d'Acoz, 2016; Tempestini, Rysgaard \& Dufresne, 2018; Jażdżewska \& Mamos, 2019) and

97 revealed the existence of cryptic species complexes within widely distributed taxa (Witt,

98 Therloff \& Hebert, 2006; Mamos et al., 2014; Wysocka et al., 2014; Havermans, 2016).

99 Amphipoda are not only a species-rich group, but they also often dominate the crustacean

100 assemblages in which they occur (e.g., Corkum, 1989; Humphries, Davies \& Mulcahy, 1996;

101 Vinogradov, Volkov \& Semenova, 1996; Jazdzewski et al., 2001; Väinölä et al., 2008; Frutos,

102 Brandt \& Sorbe, 2017; Brix et al., 2018; Havermans \& Smetacek, 2018). They can be found in

103 both the benthos and the pelagic realm, presenting a variety of states of mobility (from

104 epibenthic clingers to fully mobile swimmers) and, as a result, possess a wide variety of feeding

105 habits including herbivory, detritivory, necrophagy, omnivory, predation and ectoparasitism

106 (Barnard \& Karaman, 1991; Vinogradov, Volkov \& Semenova, 1996; Dauby, Scailteur \& De

107 Broyer, 2001; Väinölä et al., 2008). Being diverse and abundant they are important prey items

108 for other invertebrates and vertebrates, including fish, birds and mammals (e.g. Dalpadado et al., 109 2001; Dauby, Nyssen \& De Broyer, 2003). Certain species of Amphipoda are used in laboratory

110 ecotoxicological studies (Hyne \& Everett, 1998; Bundschuh et al., 2013, Major et al., 2013).

111 Some amphipod species are well-adapted to anthropogenic environments such as artificial

112 structures used in coastal protection or are part of fouling communities, and have shown a high

113 invasion potential worldwide (e.g., Bij de Vaate et al., 2002; Kelly et al., 2006; Cabezas et al.,

114 2014; Rewicz et al., 2015; Beermann et al., 2020; Sedano et al., 2020).

115 The combined factors of high diversity and the important role played by amphipods in the

116 aquatic ecosystem highlights the need for accurate species identifications which are required for 
117 biological monitoring programs. The use of DNA-barcoding may speed up the identification

118 process, but it will only succeed if the barcode library is well-established and robust. Recent gap-

119 analyses of the barcode libraries in aquatic European environments showed very large

120 differences in the coverage between different taxonomic groups and geographic regions

121 (Weigand et al., 2019; Feio et al., 2020; Hestetun et al., 2020; Leite et al., 2020; Vieira et al.

122 2021). These studies used species lists restricted to particular geographic regions or chosen

123 taxonomic groups. Basic summaries concerning the extent of amphipod data in BOLD identified

124 problems with lack of taxonomic identification or detailed geographic information as well as

125 contamination with human or bacterial DNA and provided recommendations to improve the data

126 (Radulovici \& Coleman, 2017; Coleman \& Radulovici, 2020). However, to date there are no

127 detailed analyses that have been conducted on a single taxon on a global scale.

128 In this study we have conducted a gap-analysis of the barcode library of a single crustacean

129 order, the Amphipoda, on a global basis. In producing an up-to-date picture of the current state

130 of knowledge, we will provide researchers with a detailed understanding of the both the strengths

131 and the potential limitations of the use of DNA barcodes for identifications. We also propose

132 recommendations for future initiatives that involve molecular data and produce new barcodes to

133 fill the gaps in our knowledge of this taxon.

134 Material and methods

135 Data for the present study were retrieved from BOLD by searching the "Public Data Portal"

136 using the keyword "Amphipoda". A combined dataset of all records was downloaded as an .xml

137 file on June 24th 2020.

138 All records of the barcoding fragment of the cytochrome c oxidase I (COI-5P in BOLD) were

139 extracted (29016 records). This extracted dataset was used for all further analyses conducted by 
140 using various filtering options in an Excel spreadsheet. 2579 records, represented by sequences

141 shorter than $500 \mathrm{bp}$ or having more than $1 \%$ ambiguous nucleotides for which BINs were not

142 ascribed, were removed from dataset. Continued analysis of the dataset revealed some duplicate

143 records (1468 records, 734 cases, Supplemental file 1). These derived from data harvested by

144 BOLD from GenBank and seemed to be associated with an update of the records in GenBank. In

145 the dataset, these records had an identical sample ID that referred to a GenBank Accession

146 Number but with an additional '.1' appended (e.g. KP713892 and KP713892.1) and with an

147 identical identification provided. The differences were often linked with more detailed

148 geographical information in the case of one record from the pair. Only the more detailed entry

149 was retained for continued analysis. One sequence of Niphargus novomestanus S. Karaman,

1501952 (KR858496, BOLD:ADD1128) was removed from the dataset because it was deleted from

151 GenBank by its submitter ("This record was removed at the submitter's request because the

152 source organism cannot be confirmed.” GenBank website). The resulting dataset contained

15325702 records (Fig. 1, Supplemental file 2).

154 Each record in the dataset was then further refined by sorting into categories according to the

155 level of taxonomic identification. The following categories were used: order, family, subfamily,

156 genus and species. Where records were provided with a temporary species identification, i.e.

157 they are recognised as separate morphospecies but are not determined to correspond to a known

158 taxon - they were treated as a separate category. In the whole dataset ca. $2.5 \%$ of records (596

159 individuals, 145 BINs) had uncertain identification with "cf." or "aff”. Because the majority of

160 them (417 records, 101 BINs) were associated with five species of one genus (Gammarus) for

161 simplification all such records were treated as final species identifications. However, it is

162 understood that the use of open nomenclature, when applied to identifications, provides an 
163 indication of the level of uncertainty, and may be intended to indicate the presence of new

164 species or species complexes.

165 The data in BOLD come from wide variety of projects, some of which involve detailed

166 taxonomic study by specialists, others are focused on monitoring or other topics in which

167 taxonomic specialists are not involved. For the purposes of our analyses it was assumed that the

168 identification accuracy was equal throughout the whole dataset, regardless of its origin. In

169 several cases identification of the specimens within a single BIN varied strongly, with some

170 records remaining at order level while others were determined to the species level. BINs aim to

171 represent a putative species, so in the above example, the most detailed taxonomic information

172 was applied to all records within the single BIN. Sometimes multiple (most often two) species or

173 genus names were associated with a single BIN (87 cases). Each of these cases was checked

174 individually. Sometimes it was an obvious misidentification of a single individual within a large

175 group - if this was noted the misidentified record was added as an additional element to the

176 records identified to the lowest congruent level (e.g. if the genus name matched the BIN genus,

177 the misidentified taxon was added as an additional record identified to the genus level, if the

178 lowest congruent level was family it was added to the family records); and the taxon

179 identification of the majority of records was applied as correct. When it was impossible to judge

180 which name was correct, the name of the identifier was checked and identifications carried out

181 by taxonomists specializing in Amphipoda was prioritised over a that provided by a non-

182 specialist study. Where this process did not give a satisfactory conclusion, the BIN was allocated

183 an identification at a rank that was congruent for the different records. The list of taxa with

184 incongruent identifications together with an explanation of the final decision is presented in

185 Supplemental file 3.

Peer] reviewing PDF | (2021:06:62492:1:1:NEW 21 Sep 2021) 
186 Based on the taxonomic identification of the records the associated BINs were divided into the

187 following environmental categories:

188 a) marine

189 b) freshwater

190 c) terrestrial.

191 Taxa that inhabit both marine realm and brackish environments were allocated to the marine 192 category. Taxa from freshwater also occurring in brackish waters were allocated to the

193 freshwater category. All representatives of the family Talitridae were treated as terrestrial taxa.

194 Where taxonomic information was not detailed enough to provide environmental information

195 about the particular BIN, the geographic data (coordinates and/or locality description) of the

196 associated records were used to ascribe a particular BIN to one of the above categories. In some

197 cases, this necessitated checking the original publication. A small number of unallocated BINs

198 (18) and associated records (44) were used only in the first general summary of amphipod

199 barcodes, but they were removed from further analyses (Supplemental file 4).

200 In order to verify the correct environmental allocation of BINs, all BINs with records possessing

201 coordinates were plotted on a map using the software QGIS2.16.1 (QGIS Development Team,

202 2018). Cases where incongruence between the ascribed environment and the geographic position

203 appeared were checked individually. For those records without detailed geographic information

204 the country of origin was taken from either BOLD or the associated publication.

205 In order to verify the barcode coverage within the studied group a list of BINs associated with a

206 species name was compared with the list of accepted amphipod species names available in the

207 World Amphipoda Database (WAD, Horton et al., 2020, accessed on 17-07-2020). A barcode

208 quality assessment of the species represented in BOLD, based on the grading system proposed 
209 by Oliveira et al. (2016) and slightly modified by Fontes et al. (2020) was applied. This system

210 consists of five grades: A - consolidated concordance ( $>10$ sequences of a single morphospecies

211 grouped in a single BIN), B - basal concordance (same as grade A but between three and 10

212 sequences available in the library), $\mathrm{C}$ - multiple BINs (one morphospecies assigned to more than

213 one BIN), D - insufficient data (single species is assigned to single BIN but it is represented by

214 less than three sequences in the barcode library), E - discordant species assignment (more than

215 one species assigned to a single BIN). Fontes et al. (2020) provide an R-based application

216 (Barcode, Audit \& Grad System - BAGS), and uses only those records possessing species

217 names. Since our aim was to focus on all available barcode records (including sequences

218 identified only to higher ranks), the assessment was carried out manually. Additionally, as a

219 result of initial treatment of the dataset, misidentified species records or BINs with unclear

220 species identification, were already removed, so category E (discordant species assignment,

221 Oliveira et al., 2016; Fontes et al., 2020) was not recorded. For the purpose of the present study

222 Lysianassoidea incertae sedis was treated as an additional family. The amphipod families were

223 divided into four categories depending on the number of species in each: low species rich

224 families (up to 10 species), moderately species rich families (from 11 to 30 species), species rich

225 families (31-100 species), very species rich families (more than 100 species). This division

226 allowed verification of pattern between the species richness of the family and its representation

227 in BOLD.

\section{Results}

229 Of the 25702 amphipod COI records, 46.5\% (11958 records) were freshwater, 43.5\% (11169

230 records) were from the marine realm, and 9.8\% (2531 records) were terrestrial taxa. Of the 3835

231 recognized BINs in total, 45\% (1726 BINs) belonged to freshwater taxa, 50\% (1920 BINs) were 
232 marine, and 4.5\% (171 BINs) were from terrestrial taxa. 44 records $(0.2 \%)$ and their associated

23318 BINs $(0.5 \%)$ could not be ascribed to the above environmental categories and were not

234 considered further (Fig. 2A, B).

235 More than half (57.5\%) of the records available in BOLD possessed coordinates, and 20\% had

236 information about the country of origin. Geographic information about the remaining $22.5 \%$ was

237 provided only in the original publication. Geographic information is more comprehensive for

238 marine taxa, where $71 \%$ of records possessed coordinates (compared to $47 \%$ for freshwater, and

$23950 \%$ for terrestrial taxa). Molecular studies of freshwater Amphipoda are focused mainly in the

240 Northern hemisphere (particularly European countries, Russia and United States) while in the

241 Southern hemisphere, Australia, New Zealand and Argentina are well studied (Fig. 3A). There is

242 a complete lack of records (amphipod sequences) from Brazil, equatorial America and vast areas

243 of Africa. Similar patterns of data coverage were seen for marine amphipods, which have greater

244 numbers of records along European, North American and East Asian coasts. In the Southern

245 hemisphere, Australia, New Zealand and Antarctica had larger numbers of barcode records (Fig.

246 3B). However, vast areas of the deep sea and the Arctic Ocean remain undersampled. Terrestrial

247 Amphipoda in Europe, North America, China, Australia and Chile were the best represented

248 (Fig. 3C), but sampling gaps were seen in the continents of South America and Africa.

249 The majority of records $(69.8 \%, 17922$ recs.) had a complete species-level identification. Of the

250 remaining $30.2 \%$ of records, $5.6 \%$ (1433 recs.) had received temporary names (open

251 nomenclature), $11.3 \%$ (2902 recs.) remained identified at the genus level, $0.2 \%$ (40 recs.) at

252 subfamily, 5.0\% (1285 recs.) at family, and 8.1\% (2076 recs.) at the order level. Levels of

253 identification varied according to the environment, with marine taxa having greater proportions

254 of taxa identified only to higher taxonomic ranks (Fig. 4A). The majority of BINs (3817) were 
255 associated with species names $(55.7 \%, 2126$ BINs). These were followed by BINs identified to

256 the order level (13.3\%, 506 BINs), generic or family level (10.7\%, 407 BINs each) and those

257 with a temporary name $(9.4 \%, 359)$. BINs with only a subfamily name constituted just $0.3 \%$

258 (12). Greater variations between environments were seen for the BINs, with 74\% (1284) of

259 freshwater BINs having a species level identification, compared to only $39 \%$ (751) of marine

260 BINs (Fig. 4B). More than 20\% (444, 23\%) of the BINs for marine taxa remained identified at

261 the order level.

262 Regardless of the environmental origin, the majority of BINs were represented by a single

263 sequence (Fig. 5). BINs represented by five or fewer sequences constituted around two thirds

$264(67 \%, 114$ terrestrial BINs to three quarters, 78\%, 1488 marine BINs) of BINs recorded in a

265 particular environment. Freshwater taxa had 41 BINs (2.4\%) represented by more than 50

266 sequences, compared to $28(1.5 \%)$ for marine taxa, and eight $(4.7 \%)$ for terrestrial taxa. When

267 only those BINs with complete species-level identifications are considered, the proportion of

268 sequences representing a particular MOTU does not change, with freshwater taxa having $78 \%$ of

269 BINs (1016) represented by five or fewer sequences. Almost three quarters of marine BINs

$270(71 \%, 525 \mathrm{BINs})$ had five or fewer sequences in BOLD, while this proportion was $61 \%$ (56

271 BINs) for terrestrial taxa. Freshwater taxa had 35 BINs (3\%) represented by more than 50

272 sequences, compared to $27(4 \%)$ for marine taxa, and $6(7 \%)$ for terrestrial taxa. The best

273 represented BIN in BOLD (801 sequences) belonged to the terrestrial species Orchestoidea

274 tuberculata Nicolet, 1849 (BOLD:ACQ3380), followed by the marine species Gammarus

275 oceanicus Segestråle, 1947 (BOLD:AAA1262, 553 sequences), and the freshwater species

276 Diporeia hoyi (S.I. Smith, 1874) (BOLD:AAA1473, 512 sequences). A further 26 BINs were 
277 represented by more than 100 sequences, including 17 freshwater, seven marine and two

278 terrestrial BINs (Supplemental file 5).

279 Out of the 3817 studied BINs, just over half $(55.7 \%, 2126)$ were associated with a species-level 280 identification, representing 1001 species. Freshwater BINs with species identification reached 281 1284, associated with 453 species, while 751 marine BINs were determined to 496 species. Of 282 the 91 terrestrial BINs, 52 species were identified. Generally, a single morphological species was 283 associated with each BIN (68\%, 680 cases, 288 in freshwater, 359 marine, 33 terrestrial). 17\% of 284 the identified species were associated with two different BINs (72 freshwater, 82 marine and 14 terrestrial) (Fig. 6). There were however 19 cases when one single morphological species was represented by more than 10 BINs (17 freshwater, one marine and one terrestrial) (Supplemental file 6). The greatest number of BINs was recorded for the freshwater species Gammarus balcanicus Schäferna, 1923 represented by 143 BINs (45 BINs were identified as “cf.” or “aff.”) followed by another freshwater taxon Hyallella azteca (Saussure, 1858) (62 BINs) and Gammarus fossarum Koch, 1836 (51 BINs; 19 BINs identified as “cf.” or "aff."). Among terrestrial taxa the highest molecular variation (12 BINs) was recorded for Morinoia japonica

292 (Tattersall, 1922) (present in BOLD under former generic name Platorchestia), while Apohyale stebbingi Chevreux, 1888 (with 11 BINs recognized) was the most diverse among marine 294 species.

295 Of the 239 accepted families of Amphipoda (238 families and Lysianassoidea incertae sedis), $296105(44 \%)$ were represented by at least one species in BOLD (Table 1). The largest number of 297 families had up to $20 \%$ of species barcoded, while only ten families had more than half of the 298 known species barcoded (Supplemental file 7). Thirteen families lacking barcoded species had at 
299 least one barcoded taxon identified at the genus level, a further five families had a taxon

300 identified at the family level.

301 Just under ten percent (999 spp., 9.7\%) of the 10330 accepted species of Amphipoda (Horton et

302 al., 2020) had barcodes. Of the nominal species possessing barcodes almost 500 (496 spp.) are

303 marine, $451 \mathrm{spp}$. are freshwater and $52 \mathrm{spp}$. are terrestrial taxa. The data coverage of the majority

304 of species, no matter their environmental origin, is not sufficient for the barcodes to be trusted

305 according to the quality control system (Table 2) (Oliveira et al., 2016; Fontes et al., 2020).

306 Additionally, a large group of taxa is represented by multiple BINs; only $10 \%$ of species

307 represent consolidated concordance of available barcodes.

308 The breakdown of amphipod families according to the assigned categories of richness and their

309 respective representation in BOLD can be seen in Table 3. Almost every one of the very species

310 rich families had at least one species barcoded (31 families out of 32), and 22 of 30 species rich

311 families are represented in BOLD. For both moderately low and low species rich families 26

312 possessed at least one representative in BOLD constituting respectively $48 \%$ and $21 \%$ of all

313 families each (Supplemental file 7). The mean coverage of barcodes for species in each of the

314 above groups was around 10\% with the highest observed for low species rich families (12\%) and

315 the lowest (8\%) recorded for families grouping from 30 to 100 species. However, if the families

316 without any molecular information were removed from the study these numbers considerably

317 change. The low species rich families (1-10 spp.) had a barcode coverage at the level of $49 \%$,

318 moderately species rich families (11-30 spp.) reached $21 \%$ of coverage, while the rich and very

319 rich amphipod families (more than $30 \mathrm{spp}$.) had only 9-10\% of species studied.

320 A third of families (34) have at least one species characterized by consolidated concordance of

321 available barcodes (category A of the quality grading system). Another third of families (38) do 
322 not have any species in categories A or B, indicating that the species already studied represent a

323 potential cryptic diversity or the available data are insufficient (Table 4).

324 Within the very species rich families, the best representation in BOLD was recorded for

325 Niphargidae (36.5\% of known species represented with a barcode), Gammaridae (31\%) and

326 Crangonyctidae (16\%). Only the family Stegocephalidae did not have any representative with

327 species level identification (although barcodes belonging to this family but identified at genus

328 level were present). The least studied families within this group (but having at least one species

329 barcode) were: Phoxocephalidae (1\% of the species with a barcode), Dexaminidae,

330 Liljeborgiidae and Maeridae (ca. $2 \%$ of the species with a barcode). Among species rich families

$33141 \%$ of the species from Pseudoniphargidae had barcodes, while the Epimeriidae and

332 Pontogammaridae had $20 \%$ and $19 \%$, respectively. The best represented moderately species rich

333 families were Metacrangonyctidae, Oxycephalidae and Hyperiidae with $55 \%, 50 \%$ and $48 \%$ of

334 the associated species represented with a barcode respectively. Within low species rich families

335 four (Baikalogammaridae, Crymostygidae, Cyllopodidae and Tryphanidae) had all known

336 species represented with barcodes, but other than Cyllopodidae (two species) the families are

337 monotypic (Supplemental file 7).

\section{Discussion}

\section{Extent of barcode library of Amphipoda}

340 One of the aims of establishing the BOLD database was to store and publish barcodes, based on records uploaded by its users and supplemented by the data harvested from GenBank

342 (Ratnasingham \& Hebert, 2007). Together with the BIN system, that groups similar sequences in 343 clusters representing putative species (Ratnasingham \& Hebert, 2013), the BOLD database aids 344 in recognising and quantifying biodiversity. The extent of data in BOLD expresses the activity of 
345 researchers studying particular groups using molecular methods. The number of available

346 sequences of Amphipoda in BOLD is comparatively large. At the time of download (end of June

3472020 ) they were represented by almost 26000 records (3835 BINs), and by the end of August

348 there were more than 34000 public sequences (3914 BINs) (BOLD accessed on 20-08-2020),

349 indicating the great intensity of molecular studies involving this crustacean group, and that the

350 data in BOLD are actively growing. Among other crustacean groups only Decapoda is

351 represented by a higher number of records (64 281 records). Copepoda are represented by 18

352511 , Thecostraca by 15 554, Isopoda by 13858 and Branchiopoda by 12326 sequences. The

353 large number of identified BINs within the Amphipoda also places this group second only to

354 Decapoda (with 6056 BINs). Isopods and copepods are represented by 1853 and 1804 BINs,

355 respectively, while 969 BINs were identified within Branchiopoda. Within Thecostraca only 545

356 BINs were identified (boldsystems.org, accessed on 20-08-2020).

357 When the BIN system was implemented, Ratnasingham \& Hebert (2013) indicated that 12\% of

358 all the sequences available in BOLD lacked a family name, 19\% a genus name and 40\% a

359 species name. A comparison of these numbers with the present data on Amphipoda looks

360 optimistic, where only $8 \%$ of sequences are without family indication, $13 \%$ are without genus

361 and 29\% lack a species identification. However, the global analysis of Ratnasingham \& Hebert

362 (2013) identified 10\% of BINs lacking family names, almost 24\% lacking generic names and

$36346 \%$ lacking species names. These numbers are almost identical for amphipod BINs known

364 presently $(13 \%, 23 \%, 43 \%$ of BINs lacking family, genus and species information, respectively).

365 Among all known species of Amphipoda, almost $80 \%$ of species are marine, some $20 \%$ live in

366 freshwaters, while 2\% may be considered as terrestrial (Horton et al., 2020; Väinölä et al., 2008).

367 The above proportions are expressed neither in the number of records nor the number of 
368 recognized BINs that are more or less evenly distributed between freshwater and marine taxa.

369 This demonstrates that in terms of amphipod crustaceans freshwater taxa are much better studied

370 than the marine taxa. These disproportions are even more striking when the level of

371 identification of sequences and BINs is considered. Although the majority of data in BOLD

372 possess species-level identifications, marine amphipods are less thoroughly identified. This is

373 especially clear for marine BINs, of which only $39 \%$ had species-level identifications, while as

374 much as one fifth are identified only as "Amphipoda". The fact that freshwater amphipods are

375 better studied is not surprising considering the easier access to this environment. In the case of

376 marine fauna, obtaining samples suitable for molecular analysis can be challenging, especially

377 when extreme habitats (polar regions, deep-sea, hydrothermal vents etc.) are considered (e.g.,

378 Riehl et al., 2014; Jażdżewska \& Mamos, 2019). Additionally, rarity is a common feature of

379 numerous marine species (particularly in the deep-sea environment, see Kaiser et al., [2007]),

380 where many taxa are known only from their original descriptions and type localities (Jażdżewska

$381 \&$ Mamos, 2019). The question of how many of the BINs not associated with a species

382 identification actually belong to already known species is also of concern. In these cases, it is

383 highly advisable to put every effort to identify the already available material - this will relatively

384 efficiently improve data usability. Taxa that are associated with a BIN, yet are known to be new

385 to science are another cause for concern. This is particularly evident for marine taxa collected

386 during recent deep-sea exploration programs (e.g., Brandt et al., 2007; Jażdżewska, 2015; Brandt

387 et al., 2019; Brix et al., 2020). It is imperative that full scientific descriptions of new species are

388 produced to reduce the current proliferation of 'dark taxa' (Page, 2016).

389 The geographic distribution of available amphipod sequence records shows clear sampling gaps.

390 In particular the African continent, the northern part of South America and the Coral Triangle in 
391 Asia are complete "white spots" when freshwater and terrestrial taxa are considered. For marine

392 species, the coasts of Africa and South America, the Coral Triangle, and large parts of the deep

393 sea of all oceans, lack coverage. Considering the known high species diversity of these regions it

394 will be necessary to establish targeting sampling programs before we can consider that we have

395 adequate global coverage of the molecular diversity of the Amphipoda.

396 Our study shows that globally the barcoding coverage of amphipod species is only about $10 \%$. In

397 comparison, just over $20 \%$ of all species registered in the European Register of Marine Species

398 (ERMS) and almost 50\% of species listed in the AZTI Marine Biotic Index (AMBI) have been

399 barcoded (Weigand et al., 2019). The percentage of barcoded European freshwater invertebrates

400 used in environmental monitoring reaches $64.5 \%$, and when considering only Peracarida, $24 \%$ of

401 ERMS species, $45 \%$ of AMBI and $82 \%$ of freshwater monitored taxa have been barcoded

402 (Weigand et al., 2019). It has to be emphasized however, that only ERMS lists all marine

403 invertebrates from European region, while both other datasets studied by Weigand et al. (2019)

404 consists of a subset of species from this area. More specific studies of Iberian macroinvertebrates

405 revealed that ca. 40\% of amphipod species possess barcodes (Leite et al., 2020; Múrria et al.,

406 2020). Hestetun et al. (2020) conducted a barcode library gap-analysis of the benthic macrofauna

407 of one region of the North Sea, which indicated the barcode coverage varying from $42.4 \%$ to

$40861 \%$ (depending on the calculation method) while Vieira et al. (2021) found that in Macaronesia

$40934.2 \%$ to $72.6 \%$ of macroinvertebrate species have barcode representation with much better

410 coverage of non-indigenous taxa in comparison to the native ones. This indicates that for smaller

411 subset of taxa and specified geographic region it is much easier to produce good barcode

412 coverage. It can be concluded that although Amphipoda are an actively studied taxonomic group 
413 where scientists increasingly use molecular methods, this diverse and abundant macrofaunal

414 taxon is still insufficiently represented in the BOLD barcode library.

415 Quality of amphipod barcode library

416 In order to provide a trusted barcode for a particular species, at least one good quality sequence 417 associated with a species-level identification provided by taxonomic specialist is required as an 418 absolute minimum. However, a single sequence cannot provide information about intraspecific 419 variation, and overlooked contamination of the sample will mean the sequence cannot be 420 validated. As such, it is advisable to provide a small number of sequences to characterise each 421 taxon. The recently proposed barcode quality auditing system suggests providing at least three 422 sequences to enable proper barcode evaluation (Oliveira et al., 2016; Fontes et al., 2020).

423 Unfortunately, as we have shown in the case of Amphipoda, globally more than half of BINs are 424 represented by only 1-2 sequences in BOLD. This low number of sequences places them in 425 category D of the Oliveira et al. (2016) system, indicating the existing data is insufficient for use 426 as trusted barcodes. Similar observations for a restricted amphipod dataset are made by Fontes et 427 al. (2020).

428 Due to methodological differences it is impossible to make direct comparisons of our data with 429 the results of the gap analysis of aquatic organisms in European waters (Weigand et al., 2019), 430 but re-calculation of their data shows much improved barcode coverage. Among all freshwater 431 invertebrates $65 \%$ of taxa barcoded are represented by more than five sequences, while this 432 percentage rises to $77 \%$ when considering only freshwater Peracarida. This proportion of high 433 quality datasets diminishes when marine taxa are considered; with $52 \%$ of the marine species 434 from the AMBI list and 45\% those listed in ERMS having at least five barcodes available. These 435 numbers do not change when considering only marine Peracarida (52\% and $46 \%$ of the ones 
436 presented in AMBI and ERMS lists, respectively). Our analysis of Amphipoda shows opposite

437 pattern with about $1 / 4-1 / 3$ of BINs represented by more than five sequences but the good

438 barcode coverage observed by Weigand et al. (2019) may be biased by the fact that they targeted

439 the species used in water quality assessment programs. Because of their practical use such taxa

440 receive more scientific interest and it may be assumed that their barcoding is prioritized by

441 different institutions.

442 The amphipod BINs that have the largest numbers of sequences in BOLD are often the result of

443 detailed studies of targeted species, which have produced large numbers of sequences as a

444 secondary aim of the study. For example, 750 out of the 801 sequences in BOLD of terrestrial

445 Orchestoidea tuberculata come from a single study by Brante et al. (2019); 406 records out of

446411 sequences in BOLD of freshwater Dikerogammarus haemobaphes (Eichwald, 1841) come

447 from Jażdżewska et al. (2020); while 232 records of 235 sequences in BOLD of marine Caprella

448 scaura Templeton, 1836 come from Cabezas et al. (2014). The disproportional representation

449 between the few species that are very thoroughly studied and the remaining majority of species

450 that are represented only by a single, or a low number of sequences emphasises the need for

451 more targeted sampling of less common species.

\section{Best studied families and cryptic diversity}

453 Almost half of the 239 known amphipod families are represented in BOLD. However, only ten

454 of these families have more than $50 \%$ of their associated species sequenced. It is important to

455 underline that there are 18 families in BOLD that do not have species-level identifications, but

456 have records left at the family or genus level. A small effort to provide trusted species-level

457 identifications for these taxa will greatly improve barcode coverage of the Amphipoda,

458 particularly if they represent species already known to science. 
459 Another concern that has arisen as part of this study relates to the format of temporary names in

460 GenBank and BOLD, the different requirements by users for their input, and how this has

461 changed following development of the databases. In GenBank, the incorporation of temporary

462 names or codes is allowed (referred to as placeholder names in GenBank). In 2010, a large

463 amount of COI data was incorporated into the BOLD database. The identifications associated

464 with each of these imported sequences were included verbatim from GenBank. BOLD users,

465 however, were originally able to use temporary names in the database only in private

466 projects/dataset and when opening their data for public they were expected to provide the

467 identification to the lowest taxonomic level possible (e.g. genus) and to provide the temporary

468 name (e.g. incorporating "cf." or "aff.") as a taxonomy note (that has happened to the authors of

469 the present paper). However, in BOLD a taxonomy note is only visible when the specimen page

470 is open, and not in a general search. Recently, we have learnt that open nomenclature identifiers

471 (such as 'cf.' and 'aff.') are accepted by BOLD, but it may be assumed that numerous records

472 remain at a higher taxonomic level, with more detailed identifications available that are hidden

473 from general searches. This discrepancy in dealing with temporary names has become apparent

474 when analysing the whole dataset as part of this study. In particular, the inconsistent use of

475 temporary names in these databases mean that it is very difficult to differentiate between

476 temporary names which are being used to refer to species that are new to science, and those

477 which have remained at a higher taxonomic level because they were simply not identified further

478 (which could be for a variety of reasons). Molecularly well-defined temporary names for new

479 species are likely to become more abundant and therefore critical to our knowledge of

480 biodiversity in the coming years, and we need to ensure they are managed carefully and

481 consistently. Recommendations for the use of open nomenclature have been proposed recently to 
482 attempt to standardise and overcome these issues (Sigovini, Keppel \& Tagliapietra, 2016; Horton

483 et al., 2021) and it is hoped that these standard formats will be considered for use in both BOLD

484 and GenBank.

485 Barcode coverage of families varies depending on the species richness. For species rich families

486 it is around $10 \%$, while coverage is increased for moderate and low species rich taxa. This is not

487 surprising considering it is much easier to receive better coverage for monotypic families or

488 those represented by only a few species. The best studied families are the ones that remain under

489 the interest of large working groups who focus on studying specific families (e.g. Hou, Fu \& Li,

490 2007; Mamos et al., 2014; Wysocka et al., 2014; Delić et al., 2017a; Delić et al., 2017b; Fišer et

491 al., 2017; Copilaş-Ciocianu, Sidorov \& Gontcharov, 2019). It is worth noting that providing

492 barcodes is generally more a "by-product" of other analyses than the goal per se. Another issue

493 that should be emphasized is that species rich families are proportionally under studied. This is

494 important because they usually do not only group many species but very often the species from

495 these families constitute the majority of amphipods characterizing different assemblages. This is

496 clearly shown by the Phoxocephalidae (1\% of the 367 known species are barcoded),

497 Ampeliscidae (7\% of 312 of the known species barcoded) or Oedicerotidae (10\% of the 246

498 known species barcoded), all constitute very large and important components of marine benthic

499 communities worldwide (Brandt, 1993; Weisshappel \& Svavarsson, 1998; Frutos \& Sorbe, 2017;

500 Brix et al., 2018). Another example is provided by the Caprellidae ( $6 \%$ of the 443 known species

501 are barcoded) which are an important part of many fouling communities (e.g., Ros, Vázquez-

502 Luis \& Guerra-García, 2013; Ros et al., 2013) and where proper species identifications are

503 crucial in the context of growing transport with their resulting potential alien species invasions 
504 (op. cit.). The studies of these families should be prioritized in order to support marine

505 monitoring programs based on barcode libraries.

506 The analysis of the amphipod BINs with a species-level identification showed that there were

507 only a few cases where multiple names were associated with a single molecular unit. A quarter

508 of these cases resulted from the misidentification of single individuals within a taxon. In some

509 cases different names were associated with the description of new species (present in the

510 database under both former and newly established name). Problems with morphological

511 identification of cryptic species and the lack of well-established diagnostic characters within

512 closely related species may also be the reason of the presence of multiple names for single BIN.

513 The above problems have been recognized within Gammarus ochridensis Schäferna, 1926

514 species complex that is the group of morphologically very similar species of which two

515 Gammarus cryptosalemaai Grabowski, Wysocka \& Mamos, 2017 and Gammarus

516 cryptoparechiniformis Grabowski, Wysocka \& Mamos, 2017 are recognizable only based on

517 molecular data (Wysocka et al., 2013; Grabowski, Wysocka \& Mamos, 2017). This indicates that

518 generally BOLD may be considered a trusted tool for species identification. Our analyses

519 showed that in the majority of cases, a single BIN was characterising a single species, which is

520 congruent with the results of other similar studies (Fontes et al., 2020; Leite et al., 2020). Some

521 morphologically identified species were represented by two or even three BINs, which can

522 indicate overlooked diversity. It has been noted however, that sometimes due to the methodology

523 used during BIN-identification and the threshold used ( $2 \%$ of similarity, Ratnasingham \&

524 Hebert, 2013) some valid species may be split into two or more BINs (Lörz, Jażdżewska \&

525 Brandt, 2018; Jażdżewska \& Mamos, 2019). This happens more frequently when the sample size

526 is small and the intraspecific variation range cannot be adequately assessed. In such cases, the 
527 use of additional genes or other data analysing methods may help to decide the proper species

528 delineation. The present study revealed 19 morphological species that were represented by 11 or

529 more BINs. This multi-BIN representation was much more common in freshwater environments,

530 where 17 species with potential cryptic diversity were observed. The existence of such high

531 cryptic diversity especially in European waters was recognized by authors of the original works

532 (Witt, Threloff \& Hebert, 2006; Bauzà-Ribot et al., 2011; Major et al., 2013; Mamos et al., 2014;

533 Wysocka et al., 2014; Delić et al., 2017a; Delić et al., 2017b, Fišer et al., 2017; Tomikawa et al.,

534 2017) most recently confirmed also by Wattier et al. (2020). A detailed study of the available

535 barcodes and cryptic diversity of the Gammaridae and other representatives of the superfamily

536 Gammaroidea is in preparation (Mamos pers. comm.). The large representation of freshwater

537 taxa forming cryptic species complexes (especially in Europe) can be partly explained by the

538 geological events that shaped the European freshwater system (Wysocka et al., 2014; Mamos et

539 al., 2016; Wattier et al., 2020). Presence of marine cryptic or pseudo-cryptic species have also

540 been reported (Havermans, 2016; Verheye, Backeljau \& d'Udekem d'Acoz, 2016), but the extent

541 of molecular studies of amphipods from this realm is much smaller and as a result cryptic species

542 may have been overlooked. A study of the marine genus Apohyale showed high diversification

543 of species within the genus, and confirms that more studies are required to correctly identify

544 species diversity and uncover cryptic diversity in marine taxa (Desiderato et al., 2019). Cases of

545 highly diverse nominative species usually come from studies based in a single research group

546 that was already aware of the high diversity within the taxon. There are, however, cases where

547 multiple BINs have received the same identification but this was carried out by different authors

548 at different times (without comparison of the material) and it is difficult to judge if the observed

549 diversity is a result of the existence of a cryptic species or of misidentification of the species. In 
550 such cases it is impossible to decide which of the BINs represents the known species and which

551 are cryptic/new species that require more detailed study (Jażdżewska et al., 2018). A detailed

552 analysis of the species represented by several BINs was not the focus of the present study, but it

553 should be a priority for BOLD to identify such cases and inform users about the presence of

554 possible cryptic taxa. Users of BOLD who seek to obtain identification for their own sequence

555 should be notified that the specimen they have may belong to a group of cryptic species so that

556 the taxonomic identification can be treated with caution. Some initiatives to improve the curation

557 of BOLD data have already begun (Radulovici et al. 2021) and it is highly recommended that

558 mistakes or problematic issues that are found in the database are corrected and published e.g. the

559 case of Hyperiella antarctica Bovallius, 1887/H. dilatata Stebbing, 1888 which was recently

560 clarified by Havermans et al. (2019).

\section{Conclusions and Future recommendations}

562 We have conducted a gap-analysis of the barcode library using a single crustacean order, the 563 Amphipoda, as a model. The high diversity and the important role played by amphipods in the

564 aquatic ecosystem combine to highlight the need for accurate species identifications which are

565 required for biological monitoring programs. DNA-barcoding may speed up the identification

566 process, but success is dependent on the barcode library coverage and quality. Our gap analysis

567 has shown that although a large number of BINs (indicating putative species) was recognized by

568 BOLD still only $10 \%$ of the amphipod species are represented by barcodes. Moreover, the

569 majority of BINs is represent by a very low number of sequences that make them unreliable

570 according to the quality control system. The geographical coverage is poor with vast areas of

571 Africa, South America and the open ocean acting as "white gaps", also the level of barcoding

572 effort is skewed depending on the environment. 
573 As such, we make the following recommendations (in order of priority), which will improve the

574 data currently held within BOLD, and we outline steps that are needed to provide a more equal

575 coverage of the sequence data within the Amphipoda, and thus improve the utility of the

576 database for a variety of applications, including species identification and biomonitoring.

577 1. Morphological identification of the already recognised BINs (that are missing species ID) if

578 the voucher specimens are available.

579 2. Analysis of the nominal species that are represented by more than one BIN, especially if

580 identifications represented by different BINs were produced by separate working teams.

581 3. Prioritised barcoding of representatives from families that are known to be important and 582 abundant components of communities; Phoxocephalidae, Ampeliscidae, Oedicerotidae, and 583 Caprellidae should be prioritised.

584 4. Targeted sampling programs for taxa coming from geographical regions with the least 585 knowledge.

586 5. Targeted sampling to obtain more sequences for taxa present in BOLD but represented by 587 small numbers of sequences (especially singletons), from different parts of the species' range if 588 possible.

589 6. Targeted programs to sequence type specimens stored in musea or to collect and study fresh 590 individuals from type localities if types are unsuitable for analyses.

\section{References}

593 Arfianti T, Wilson S, Costello MJ. 2018. Progress in the discovery of amphipod crustaceans. 
594

595

596

597

598

599

600

601

602

603

604

605

606

607

608

609

610

611

612

613

614

615

PeerJ 6:e5187. https://doi.org/10.7717/peerj.5187

Aylagas E, Borja A, Muxika I, Rodríguez-Ezpeleta N. 2018. Adapting metabarcoding based benthic biomonitoring into routine marine ecological status assessment networks. Ecological Indicators 95:194-202. https://dx.doi.org/10.1016/j.ecolind.2018.07.044

Barnard JL, Karaman GS. 1991. The families and genera of marine gammaridean Amphipoda (except marine gammaroids). Part $1 \& 2$. Records of the Australian Museum Supplement 13:1-866.

Bauzà-Ribot MM, Jaume D, Fornós JJ, Juan C, Pons J. 2011. Islands beneath islands: phylogeography of a groundwater amphipod crustacean in the Balearic archipelago. BMC Evolutionary Biology 11(1):221. https://doi.org/10.1186/1471-2148-11-221

Beermann J, Hall-Mullen AK, Havermans C, Coolen JW, Crooijmans RP, Dibbits B, Held C, Desiderato A. 2020. Ancient globetrotters - connectivity and putative native ranges of two cosmopolitan biofouling amphipods. PeerJ 8:e9613 https://doi.org/10.7717/peerj.9613

Bij de Vaate A, Jazdzewski K, Ketelaars HAM, Gollasch S, Van der Velde G. 2002. Geographical patterns in range extension of Ponto-Caspian macroinvertebrate species in Europe. Canadian Journal of Fisheries and Aquatic Science 59:1159-1174. https://doi.org/10.1139/f02-098

Brandt A. 1993. Composition, abundance, and diversity of peracarid crustaceans on a transect of the Kolbeinsey Ridge, north of Iceland. Polar Biology 13:565-576. https://doi.org/10.1007/BF00236399

Brandt A, Alalykina I, Brix S, Brenke N, Blażewicz M, Golovan OA, Johannsen N, Hrinko AM, Jażdżewska AM, Jeskulke K, Kamenev GM, Lavrenteva AV, Malyutina MV, 
616

617

618

619

620

621

622

623

624

625

626

627

628

629

630

631

632

633

634

635

636

637

638

Riehl T, Lins L. 2019. Depth zonation of deep-sea macrofauna of the Northwest Pacific. Progress in Oceanography https://doi.org/10.1016/j.pocean.2019.102131

Brandt A, De Broyer C, De Mesel I, Ellingsen K, Gooday A, Hilbig B, Linse K, Thomson MR, Tyler P. 2007. The biodiversity of the deep Southern Ocean benthos. Philosophical Transactions of the Royal Society B Biological Sciences 362:39-66.

https://doi.org/10.1098/rstb.2006.1952

Brante A, Guzmán-Rendón G, Barría EM, Guillemin ML, Vera-Escalona I, Hernández CE. 2019. Post-disturbance genetic changes: the impact of the 2010 mega-earthquake and tsunami on Chilean sandy beach fauna. Scientific Reports 9(1):1-12. https://doi.org/10.1038/s41598-019-50525-1

Brix S, Lörz A-N, Jażdżewska A, Hughes L, Tandberg AH, Pabis K, Stransky B, KrappSchickel T, Sorbe J-C, Hendrycks E, Vader WJM, Frutos I, Horton T, Jażdżewski K, Peart R, Beermann J, Coleman CO, Buhl-Mortensen L, Corbari L, Havermans C, Tato R, Jimenez Campean A. 2018. Amphipod family distributions around Iceland. Zookeys 731:41-53. https://doi.org/10.3897/zookeys.731.19854

Brix S, Osborn KJ, Kaiser S, Truskey SB, Schnurr SM, Brenke N, Malyutina M, Martinez Arbizu P. 2020. Adult life strategy affects distribution patterns in abyssal isopods implications for conservation in Pacific nodule areas. Biogeosciences 17: 6163-6184. https://doi.org/10.5194/bg-17-6163-2020

Bundschuh M, Zubrod JP, Klemm P, Elsaesser D, Stang C, Schulz R. 2013. Effects of peak exposure scenarios on Gammarus fossarum using field relevant pesticide mixtures. Ecotoxicological Environment Safety 95:137-143 https://doi.org/10.1016/j.ecoenv.2013.05.025 
639 Bush A, Compson ZG, Monk WA, Porter TM, Steeves R, Emilson EJ, Gagne N,

640 Hajibabaei M, Roy M, Baird DJ. 2019. Studying ecosystems with DNA metabarcoding:

641 lessons from biomonitoring of aquatic macroinvertebrates. Frontiers in Ecology and

$642 \quad$ Evolution 7 (434) http://dx.doi.org/10.3389/fevo.2019.00434

643 Cabezas MP, Xavier R, Branco M, Santos AM, Guerra-Garcia JM. 2014. Invasion history of

644 Caprella scaura Templeton, 1836 (Amphipoda: Caprellidae) in the Iberian Peninsula: multiple

645 introductions revealed by mitochondrial sequence data. Biological Invasions 16:2221-2245.

646 https://doi.org/10.1007/s10530-014-0660-y

647 Coleman CO. 2015. Taxonomy in Times of the Taxonomic Impediment - Examples from the

648 Community of Experts on Amphipod Crustaceans. Journal of Crustacean Biology 35(6):729-

649 740. https://doi.org/10.1163/1937240X-00002381

650 Coleman CO, Radulovici AE. 2020. Challenges for the future of taxonomy: talents, databases

651 and knowledge growth. Megataxa 001(1):028-034. https://doi.org/10.11646/megataxa.1.1.5

652 Copilaş-Ciocianu D, Sidorov D, Gontcharov A. 2019. Adrift across tectonic plates: molecular

653 phylogenetics supports the ancient Laurasian origin of old limnic crangonyctid amphipods.

654 Organisms, Diversity and Evolution 19:191-207. https://doi.org/10.1007/s13127-019-00401-

$655 \quad 7$

656 Corkum LD. 1989. Patterns of benthic invertebrate assemblages in rivers of northwestern North

657 America. Freshwater Biology 21:191-205. https://doi.org/10.1111/i.1365-

$658 \quad \underline{2427.1989 . t b 01358 . x}$

659 Cowart DA, Pinheiro M, Mouchel O, Maguer M, Grall J, Miné J, Arnaud-Haond S. 2015.

660 Metabarcoding Is Powerful yet Still Blind: A Comparative Analysis of Morphological and 
661

662

663

664

665

666

667

668

669

670

671

672

673

674

675

676

677

678

679

680

681

682

Molecular Surveys of Seagrass Communities. PLoS ONE 10(2):e0117562.

https://doi.org/10.1371/journal.pone.0117562

Cristescu ME. 2014. From barcoding single individuals to metabarcoding biological communities: Towards an integrative approach to the study of global biodiversity. Trends in Ecology and Evolution 29(10):566-571. http://dx.doi.org/10.1016/j.tree.2014.08.001

Dalpadado P, Borkner N, Bogstad B, Mehl S. 2001. Distribution of Themisto (Amphipoda) spp. in the Barents Sea and predator-prey interactions. ICES Journal of Marine Sciences 58:876-895. https://doi.org/10.1006/jmsc.2001.1078

Dauby P, Nyssen F, De Broyer C. 2003. Amphipods as food sources for higher trophic levels in the Southern Ocean: a synthesis. In: Huiskes AHL, Gieskes WWC, Rozema J, Schorno RML, van der Vies SM, Wolff WJ, editors. Antarctic Biology in a Global Context. Backhuys Publishers, Leiden, the Netherlands, 129-134.

Dauby P, Scailteur Y, De Broyer C. 2001. Trophic diversity within the eastern Weddell Sea community. Hydrobiologia 443:69-86. https://doi.org/10.1023/A:1017596120422

Delić T, Švara V, Coleman CO, Trontelj P, Fišer C. 2017a. The giant cryptic amphipod species of the subterranean genus Niphargus (Crustacea, Amphipoda). Zoologica Scripta 46(6):740-752. https://doi.org/10.1111/zsc.12252

Delić T, Trontelj P, Rendoš M, Fišer C. 2017b. The importance of naming cryptic species and the conservation of endemic subterranean amphipods. Scientific Reports 7(1):1-12. https://doi.org/10.1038/s41598-017-02938-z

Desiderato A, Costa FO, Serejo CS, Abbiati M, Queiroga H, Vieira PE. 2019. Macaronesian islands as promoters of diversification in amphipods: The remarkable case of the family 
683

684

685

686

687

688

689

690

691

692

693

694

695

696

697

698

699

700

701

702

703

704

705

Hyalidae (Crustacea, Amphipoda). Zoologica Scripta 48:359- 375.

https://doi.org/10.1111/zsc.12339

Duarte S, Vieira PE, Costa FO. 2020. Assessment of species gaps in DNA barcode libraries of non-indigenous species (NIS) occurring in European coastal regions. Metabarcoding and Metagenomics 4:35-46. https://doi.org/10.3897/mbmg.4.55162

Ebach MC, Valdecasas AG, Wheeler QD. 2011. Impediments to taxonomy and users of taxonomy: accessibility and impact evaluation. Cladistics 27(5):550-557. https://doi.org/10.1111/j.1096-0031.2011.00348.x

Feio MJ, Filipe AF, Garcia-Raventos A, Ardura A, Calapez AR, Pujante AM, Mortágua A, Múrria C, Diaz-de-Quijano D, Martins FMS, Duarte S, Sáinz Bariáin M, Cordeiro R, Rivera SF, Väisänen LOS, Fonseca A, Gonçalves V, Garcia-Vazquez E, Vieites Rodríguez D, Ivanova EA, Costa FO, Barquín J, Rojo V, Vierna J, Fais M, Suarez M, Nieminen M, Hammers-Wirtz M, Kolmakova OV, Trusova MY, Beja P, González R, Planes S, Almeida SFP. 2020. Advances in the use of molecular tools in ecological and biodiversity assessment of aquatic ecosystems. Limnetica 39(1):419-440. https://doi.org/10.23818/limn.39.27

Fišer C, Konec M, Alther R., Švara V, Altermatt F. 2017. Taxonomic, phylogenetic and ecological diversity of Niphargus (Amphipoda: Crustacea) in the Hölloch cave system (Switzerland). Systematics and Biodiversity 15(3): 218-237 https://doi.org/10.1080/14772000.2016.1249112

Fontes JT, Vieira PE, Ekrem T, Soares P, Costa FO. 2020. BAGS: an automated Barcode, Audit \& Grade System for DNA barcode reference libraries. Molecular Ecology Resources. https://doi.org/10.1111/1755-0998.13262 
706 Frutos I, Brandt A, Sorbe JC. 2017. Deep-Sea Suprabenthic Communities: The Forgotten

707 Biodiversity. In: Rossi S, Bramanti L, Gori A, Orejas C, editors. Marine Animal Forests.

708 Springer International Publishing, Cham, p.475-503. https://doi.org/10.1007/978-3-319-

709 21012-4_21

710

711

712

713

714

715

716

717

718

719

720

721

722

723

724

725

726

Frutos I, Sorbe JC. 2017. Suprabenthic assemblages from the Capbreton area (SE Bay of Biscay): faunal recovery after a canyon turbiditic disturbance. Deep-Sea Research I 130:36-46. https://doi.org/10.1016/j.dsr.2017.10.007

Grabowski M, Wysocka A, Mamos T. 2017. Molecular species delimitation methods provide new insight into taxonomy of the endemic gammarid species flock from the ancient Lake Ohrid. Zoological Journal of the Linnean Society-London 181(2):272-285. https://doi.org/10.1093/zoolinnean/zlw025

Hajibabaei M, Spall JL, Shokralla S, van Konynenburg S. 2012. Assessing biodiversity of a freshwater benthic macroinvertebrate community through non-destructive environmental barcoding of DNA from preservative ethanol. BMC Ecology 12:28 http://dx.doi.org/10.1186/1472-6785-12-28

Havermans C. 2016. Have we so far only seen the tip of the iceberg? Exploring species diversity and distribution of the giant amphipod Eurythenes. Biodiversity 17:12-25 https://doi.org/10.1080/14888386.2016.1172257

Havermans C, Hagen W, Zeidler W, Held C, Auel H. 2019. A survival pack for escaping predation in the open ocean: amphipod-pteropod associations in the Southern Ocean. Marine Biodiversity 49(3):1361-1370. https://doi.org/10.1007/s12526-018-0916-3 
727 Havermans C, Smetacek V. 2018. Bottom-up and top-down triggers of diversification: A new

728 look at the evolutionary ecology of scavenging amphipods in the deep sea. Progress in

729

Oceanography 164:37-51. https://doi.org/10.1016/j.pocean.2018.04.008

730

731

732

733

734

735

736

737

738

739

740

741

742

743

744

745

746

747

748
Hestetun JT, Bye-Ingebrigtsen E, Nilsson RH, Glover AG, Johansen PO, Dahlgren TG. 2020. Significant taxon sampling gaps in DNA databases limit the operational use of marine macrofauna metabarcoding. Marine Biodiversity 50(5):1-9. https://doi.org/10.1007/s12526020-01093-5

Horton T, Lowry J, De Broyer C, Bellan-Santini D, Coleman CO, Corbari L, Costello M J, Daneliya M, Dauvin J-C, Fišer C, Gasca R, Grabowski M, Guerra-García JM, Hendrycks E, Hughes L, Jaume D, Jazdzewski K, Kim Y-H, King R, Krapp-Schickel T, LeCroy S, Lörz A-N, Mamos T, Senna AR, Serejo C, Sket B, Souza-Filho JF, Tandberg AH, Thomas J, Thurston M, Vader W, Väinölä R, Vonk R, White K, Zeidler W. 2020. World Amphipoda Database. Accessed at http://www.marinespecies.org/amphipoda on 1707-2020.

Horton, T. Marsh, L., Bett, B.J., Gates, A.R., Jones, D.O.B., Benoist, N.M.A., Pfeifer, S. Simon-Lledó, E. Durden, J., Vandepitte, L., Appeltans, W. 2021. Recommendations for the standardisation of open taxonomic nomenclature for image-based identifications. Frontiers in Marine Sciences, Deep-Sea Environments and Ecology https://doi.org/10.3389/fmars.2021.620702

Hou Z, Fu J, Li S. 2007. A molecular phylogeny of the genus Gammarus (Crustacea: Amphipoda) based on mitochondrial and nuclear gene sequences. Molecular Phylogenetics and Evolution 45:596-611. https://doi.org/10.1016/j.ympev.2007.06.006

Peer] reviewing PDF | (2021:06:62492:1:1:NEW 21 Sep 2021) 
749 Humphries P, Davies PE Mulcahy ME. 1996. Macroinvertebrate assemblages of littoral

750 habitats in the Macquarie and Mersey rivers, Tasmania: Implications for the management of

751 regulated rivers. Regulated Rivers: Research \& Management 12:99-122.

752 doi:10.1002/(SICI)1099-1646(199601)12:1<99::AID-RRR382>3.0.CO;2-1

753 Hyne RV, Everett DA. 1998. Application of a benthic euryhaline amphipod, Corophium sp., as

754 a sediment toxicity testing organism for both freshwater and estuarine systems. Archives of

755 Environmental Contamination and Toxicology 34(1):26-33

756 https://doi.org/10.1007/s002449900282

757 IPBES. 2019. Summary for policymakers of the global assessment report on biodiversity and

758 ecosystem services of the Intergovernmental Science-Policy Platform on Biodiversity and

759 Ecosystem Services. Díaz S, Settele J, Brondízio ES, Ngo HT, Guèze M, Agard J, Arneth A,

760 Balvanera P, Brauman KA, Butchart SHM, Chan KMA, Garibaldi LA, Ichii K, Liu J,

761 Subramanian SM, Midgley GF, Miloslavich P, Molnár Z, Obura D, Pfaff A, Polasky S,

762 Purvis A, Razzaque J, Reyers B, Roy Chowdhury R, Shin YJ, Visseren-Hamakers IJ, Willis

763 KJ, Zayas CN, editors. IPBES secretariat, Bonn, Germany; 2019.

764 Jażdżewska A. 2015. Kuril-Kamchatka deep sea revisited - insights into the amphipod abyssal

765 fauna. Deep-Sea Research II 111:294-300. https://doi.org/10.1016/j.dsr2.2014.08.008

766 Jażdżewska AM, Corbari L, Driskell A, Frutos I, Havermans C, Hendrycks E, Hughes L,

767 Lörz A-N, Stransky B, Tandberg AHS, Vader W, Brix S. 2018. A genetic fingerprint of

768 Amphipoda from Icelandic waters - the baseline for further biodiversity and biogeography

769 studies. Zookeys 731:55-73. https://doi.org/10.3897/zookeys.731.19931 
770 Jażdżewska AM, Mamos T. 2019. High species richness of Northwest Pacific deep-sea

771 amphipods revealed through DNA barcoding. Progress in Oceanography

772 https://doi.org/10.1016/j.pocean.2019.102184

773 Jażdżewska AM, Rewicz T, Mamos T, Wattier R, Bącela-Spychalska K, Grabowski M.

774 2020. Cryptic diversity and mtDNA phylogeography of the invasive demon shrimp,

775 Dikerogammarus haemobaphes (Eichwald, 1841), in Europe. NeoBiota 57:53-86.

776 https://doi.org/10.3897/neobiota.57.46699

777 Jazdzewski K, De Broyer C, Pudlarz M, Zielinski D. 2001. Seasonal fluctuations of vagile benthos in the uppermost sublittoral of a maritime Antarctic fjord. Polar Biology 24:910-917. https://doi.org/10.1007/s003000100299

780

781

782

783

784

785

786

787

788

789

790

791

Kaiser S, Barnes DK, Brandt A. 2007. Slope and deep-sea abundance across scales: Southern Ocean isopods show how complex the deep sea can be. Deep-Sea Research II 54:1776-1789. https://doi.org/10.1016/j.dsr2.2007.07.006

Kelly DW, Muirhead JR, Heath DD, MacIsaac HJ. 2006. Contrasting patterns in genetic diversity following multiple invasions of fresh and brackish waters. Molecular Ecology 15:3641-3655. https://doi.org/10.1111/j.1365-294X.2006.03012.X

Knox MA, Hogg ID, Pilditch CA. 2011. The role of vicariance and dispersal on New Zealand's estuarine biodiversity: the case of Paracorophium (Crustacea: Amphipoda). Biological Journal of the Linnean Society 103(4):863-874. https://doi.org/10.1111/j.10958312.2011.01675.x

Knox MA, Hogg ID, Pilditch CA, Lörz AN, Hebert PDN, Steinke D. 2012. Mitochondrial DNA (COI) analyses reveal that amphipod diversity is associated with environmental 
792

793

794

795

796

797

798

799

800

801

802

803

804

805

806

807

808

809

810

811

812

813

814

heterogeneity in deep-sea habitats. Molecular Ecology 21:4885-4897

https://doi.org/10.1111/j.1365-294X.2012.05729.x

Leese F, Bouchez A, Abarenkov K, Altermatt F, Borja A, Bruce K, Torbjǔrn E, Čiampor F, Čiamporová Zat'ovičová Z, Costa FO, Duarte S, Elbrecht V, Fontaneto D, Franc A, Geiger MF, Hering D, Kahlert M, Stroil BK, Kelly M, Keskin E, Liska I, Mergen P, Meissner K, Pawlowski J, Penev L, Reyjol Y, Rotter A, Steinke D, van der Wal B, Vitecek S, Zimmermann J, Weigand AM. 2018. Why we need sustainable networks bridging countries, disciplines, cultures and generations for aquatic biomonitoring 2.0: a perspective derived from the DNAqua-Net COST action. Advances in Ecological Resources 58:63-99 http://dx.doi.org/10.1016/bs.aecr.2018.01.001

Leite BR, Vieira PE, Teixeira MAL, Lobo-Arteaga J, Hollatz C, Borges LMS, Duarte S, Troncoso JS, Costa FO. 2020. Gap-analysis and annotated reference library for supporting macroinvertebrate metabarcoding in Atlantic Iberia. Regional Studies in Marine Science 101307. https://doi.org/10.1016/j.rsma.2020.101307

Lörz A-N, Jażdżewska AM, Brandt A. 2018. A new predator connecting the abyssal with the hadal in the Kuril-Kamchatka Trench, NW Pacific. PeerJ 6:e4887. https://doi.org/10.7717/peerj.4887

Major K, Soucek DJ, Giordano R, Wetzel MJ, Soto-Adames F. 2013. The common ecotoxicology laboratory strain of Hyalella azteca is genetically distinct from most wild strains sampled in eastern North America. Environmental toxicology and chemistry 32(11):2637-2647. https://doi.org/10.1002/etc.2355

Mamos T, Wattier R, Burzyński A, Grabowski M. 2016. The legacy of a vanished sea: a high level of diversification within a European freshwater amphipod species complex driven by 15 
My of Paratethys regression. Molecular Ecology 3:795-810.

816 https://doi.org/10.1111/mec.13499

Mamos T, Wattier R, Majda A, Sket B, Grabowski M. 2014. Morphological vs. molecular delineation of taxa across montane regions in Europe: the case study of Gammarus balcanicus Schäferna, 1922 (Crustacea: Amphipoda). Journal of Zoological Systematics and Evolutionary Research 52(3):237-248. https://doi.org/10.1111/jzs.12062

Mora C, Tittensor DP, Adl S, Simpson AGB, Worm B. 2011. How Many Species Are There on Earth and in the Ocean? PLoS Biology 9(8):e1001127. https://doi.org/10.1371/journal.pbio.1001127

Múrria C, Väisänen LO, Somma S, Wangensteen OS, Arnedo MA, Prat N. 2020. Towards an Iberian DNA barcode reference library of freshwater macroinvertebrates and fishes. Limnetica 39(1):73-92. http://dx.doi.org/10.23818/limn.39.06

Oliveira LM, Knebelsberger T, Landi M, Soares P, Raupach MJ, Costa FO. 2016. Assembling and auditing a comprehensive DNA barcode reference library for European marine fishes. Journal of Fish Biology 89(6):2741-2754. http://dx.doi.org/10.1111/jfb.13169

Page MJ, McKenzie JE, Bossuyt PM, Boutron I, Hoffmann TC, Mulrow CD, Shamseer L, Tetzlaff JM, AkI EA, Brennan SE, Chou R, Glanville J, Grimshaw JM, Hróbjartsson A, Lalu MM, Li T, Loder EW, Mayo-Wilson E, McDonald S, McGuinness LA, Stewart LA Thomas J, Tricco AC, Welch VA, Whiting P, Moher D. 2021. The PRISMA 2020 statement: an updated guideline for reporting systematic reviews. BMJ 372:n71. $\underline{\text { http://doi.org/10.1136/bmj.n71 }}$

Page RDM. 2016. DNA barcoding and taxonomy: dark taxa and dark texts. Philosophical Transactions of the Royal Society B 371:20150334. https://doi.org/10.1098/rstb.2015.0334 
838 QGIS Development Team. 2018. QGIS Geographic Information System. Open Source

839 Geospatial Foundation Project. http://qgis.osgeo.org.

840

841

842

843

844

845

846

847

848

849

850

851

852

853

854

855

856

857

858

859

860

Radulovici AE, Coleman CO. 2017. Reconciling large molecular datasets, bioinformatics and taxonomy: prospects for Amphipoda. Biodiversity Journal 8(2):633-634.

Radulovici AE, Vieira PE, Duarte S, Teixeira MAL, Borges LMS, Deagle B, Majaneva S, Redmond N, Schultz JA, Costa FO. 2021. Revision and annotation of DNA barcode records for marine invertebrates: report of the 8th iBOL conference hackathon. bioRxiv 2021.03.07.434272. https://doi.org/10.1101/2021.03.07.434272

Ratnasingham S, Hebert P. 2007. BOLD: The Barcode of Life Data System. Molecular Ecology Notes 7(3):355-364 https://doi.org/10.1111/j.1471-8286.2007.01678.x

Ratnasingham S, Hebert PDN. 2013. A DNA-based registry for all animal species: the barcode index number (BIN) system. PLoS ONE 8:e66213 https://doi.org/10.1371/journal.pone.0066213

Rewicz T, Wattier R, Grabowski M, Rigaud T, Bącela-Spychalska K. 2015. Out of the Black Sea: Phylogeography of the Invasive Killer Shrimp Dikerogammarus villosus across Europe. PLoS ONE 10(2):e0118121. https://doi.org/10.1371/journal.pone.0118121

Riehl T, Brenke N, Brix S, Driskell A, Kaiser S, Brandt A. 2014. Field and Laboratory Methods for DNA Studies on Deep-sea Isopod Crustaceans. Polish Polar Research 35:203224. https://doi.org/10.2478/popore-2014-0018

Ros M, Guerra-García JM, González-Macías M, Saavedra Á, López-Fe CM. 2013. Influence of fouling communities on the establishment success of alien caprellids (Crustacea: Amphipoda) in Southern Spain. Marine Biology Research 9(3):261-273.

https://doi.org/10.1080/17451000.2012.739695 
861 Ros M, Vázquez-Luis M, Guerra-García JM. 2013. The role of marinas and recreational

862 boating in the occurrence and distribution of exotic caprellids (Crustacea: Amphipoda) in the

863 Western Mediterranean: Mallorca Island as a case study. Journal of Sea Research 83:94-103.

864 https://doi.org/10.1016/j.seares.2013.04.004

865 Sayers EW, Cavanaugh M, Clark K, Ostell J, Pruitt KD, Karsch-Mizrachi I. 2020.

866 GenBank. Nucleic Acids Research 47:D94-D93. https://doi.org/10.1093/nar/gkz956.

867 Sedano F, Navarro-Barranco C, Guerra-García JM, Espinosa F. 2020. From sessile to

868 vagile: Understanding the importance of epifauna to assess the environmental impacts of

869 coastal defence structures. Estuarine, Coastal and Shelf Sciences 235:106616.

$870 \quad$ https://doi.org/10.1016/j.ecss.2020.106616

871 Sigovini M., Keppel E., Tagliapietra D. 2016. Open nomenclature in the biodiversity era. Methods in Ecology and Evolution 7:10. https://doi.org/10.1111/2041-210X.12594

873 Tempestini A, Rysgaard S, Dufresne F. 2018. Species identification and connectivity of 874 marine amphipods in Canada's three oceans. PLOS ONE 13(5): e0197174.

875 https://doi.org/10.1371/journal.pone.0197174

876 Tomikawa K, Kyono M, Kuribayashi K, Nakano T. 2017. The enigmatic groundwater

877 amphipod Awacaris kawasawai revisited: synonymisation of the genus Sternomoera, with

878 molecular phylogenetic analyses of Awacaris and Sternomoera species (Crustacea:

879 Amphipoda: Pontogeneiidae). Invertebrate Systematics 31(2):125-140.

880 https://doi.org/10.1071/IS16037

881

Väinölä R, Witt JDS, Grabowski M, Bradbury JH, Jażdżewski K, Sket B. 2008. Global

882 diversity of amphipods (Amphipoda; Crustacea) in freshwater. Hydrobiologia 595:241-255.

883 https://doi.org/10.1007/s10750-007-9020-6 
884 Verheye ML, Backeljau T, d'Udekem d'Acoz C. 2016. Looking beneath the tip of the iceberg:

885 diversification of the genus Epimeria on the Antarctic shelf (Crustacea, Amphipoda). Polar

886 Biology 39(5):925-945. https://doi.org/ 10.1007/s00300-016-1910-5

887 Vieira PE, Lavrador AS, Parente MI, Parretti P, Costa AC, Costa FO, Duarte S. 2021.

888 Gaps in DNA sequence libraries for Macaronesian marine macroinvertebrates imply decades

889 till completion and robust monitoring. Diversity and Distributions 00: 1-13.

$890 \quad$ https://doi.org/10.1111/ddi.13305

891 Vinogradov ME, Volkov AF, Semenova TN. 1996. Hyperiid Amphipods (Amphipoda,

892 Hyperiidea) of the World Oceans. Smithsonian Institution Libraries, Washington, DC.

893 Wattier, R., Mamos, T., Copilaş-Ciocianu, D., Jelić M., Ollivier A., Chaumot A., Danger M,

894 Felten V., Piscart C., Žganec K., Rewicz T., Wysocka A., Rigaud T., Grabowski M.

895 2020. Continental-scale patterns of hyper-cryptic diversity within the freshwater model taxon

896 Gammarus fossarum (Crustacea, Amphipoda). Scientific Reports 10:16536.

897 https://doi.org/10.1038/s41598-020-73739-0

898 Weigand H, Beermann AJ, Čiampor F, Costa FO, Csabai Z, Duarte S, Geiger MF,

899 Grabowski M, Rimet F, Rulik B, Strand M, Szucsich N, Weigand AM, Willassen E,

900 Wyler SA, Bouchez A, Borja A, Čiamporová Zat'ovičová Z, Ferreira S, Dijkstra KB,

901 Eisendle U, Freyhof J, Gadawski P, Graf W, Haegerbaeumer A, van der Hoorn BB,

902 Japoshvili B, Keresztes L, Keskin E, Lesse F, Macher JN, Mamos T, Paz G, Pešić V,

903 Pfannkuchen DM, Pfannkuchen MA, Price BW, Rinkevich B, Teixeira MAL, Várbíró

904 G, Ekrem T. 2019. DNA barcode reference libraries for the monitoring of aquatic biota in

905 Europe: Gap-analysis and recommendations for future work. Science of the Total

906 Environment 678:499-524. http://dx.doi.org/10.1016/j.scitotenv.2019.04.247 
907 Weisshappel JBF, Svavarsson J. 1998. Benthic amphipods (Crustacea: Malacostraca) in

908 Icelandic waters: diversity in relation to faunal patterns from shallow to intermediate deep

$909 \quad$ Arctic and North Atlantic Oceans. Marine Biology 131:133-142.

910 Witt JD, Threloff DL, Hebert PD. 2006. DNA barcoding reveals extraordinary cryptic

911 diversity in an amphipod genus: implications for desert spring conservation. Molecular

912 Ecology 15(10):3073-3082. https://doi.org/10.1111/j.1365-294X.2006.02999.x

913 Wysocka A, Grabowski M, Sworobowicz L, Burzyński A, Kilikowska A, Kostoski G, Sell J.

914 2013. A tale of time and depth: intralacustrine radiation in endemic Gammarus species flock

915 from the ancient Lake Ohrid. Zoological Journal of the Linnean Society-London 167(3):345-

916 359. https://doi.org/10.1111/j.1096-3642.2012.00878.x

917 Wysocka A, Grabowski M, Sworobowicz L, Mamos T, Burzyński A, Sell J. 2014. Origin of

918 the Lake Ohrid gammarid species flock: ancient local phylogenetic lineage diversification.

919 Journal of Biogeography 41(9):1758-1768 https://doi.org/10.1111/jbi.12335

\section{Figure captions}

921 Figure 1. PRISMA 2020 work-flow diagram (Page et al., 2021). Summary of the data download,

922 identification and screening before analysis. All record removals were done by the leading

923 author of the paper.

924 Figure 2. Environmental origin of the amphipod records (A) and BINs (B) in BOLD database.

925 Figure 3. Geographic distribution of amphipod records expressed by sequences present in BOLD

926 (A - freshwater, $\mathrm{B}$ - marine, $\mathrm{C}-$ terrestrial). Dots indicate records with exact coordinates, for

927 records without latitude and longitude the country of origin was checked. Background color

928 of the country indicates this number per country. 
929 Figure 4. Proportion of records (A) and BINs (B) with different level of identification within 930 freshwater, marine and terrestrial amphipod taxa.

931 Figure 5. Number of BINs represented by given number of sequences. Upper set (A, B, C) - all

932 BINs, lower set (D, E, F) - only BINs with complete species-level identification considered.

933 A, D - freshwater, B, E - marine, C, F - terrestrial taxa.

934 Figure 6. Number of nominal species represented by given number of BINs.

935

936 Supplemental files list

937

938 Supplemental file 1

939 - File format .xlsx

940 - Title: List of the doubled records indentified in the original dataset

941 - Description: The file consists of records that appeared to be doubled in the BOLD database.

942

943 Supplemental file 2

944 - File format .xlsx

945 - Title: The list of records analysed (after removal of doubled records).

946 - Description: The file consists of all records that was basis of the present study. The colors of

947 the cell of recordID indicates the environment: green - marine (including brakishwater and

948 fully marine taxa), red - freshwater (including freshwater and brakishwater taxa), yellow -

949 terrestrial, blue - environment not recorded.

950

951 Supplemental file 3

952 - File format .xlsx

953 - Title: List of BINs possessing more than one ID variant with notes on the identification

954 - Description: The file presents BINs that have received different identifications with details of

955 the ID and comments concerning the final identification used in the study. 


\section{Supplemental file 4}

958 - File format .xlsx

959 - Title: List of BINs for which the environment was not able to be assessed.

960 - Description: The file presents BINs for which the available data did not allow to specify the

961 environment.

962

\section{Supplemental file 5}

964 - File format .xlsx

965 - Title: List of BINs with the largest number of records (blue - freshwater, green - marine, yellow

$966-$ terrestrial taxa).

967 - Description: The file presents BINs that are represented by the largest number of records. The

968 information about environmental origin of associated species are provided.

969

\section{Supplemental file 6}

971 - File format .xlsx

972 - Title: Nominal species with the largest number of BINs identified.

973 - Description: The file presents nominal species for which the largest number of BINs has been

974 identified. Environmental origin of species is also provided.

975

\section{Supplemental file 7}

977 - File format .xlsx

978 - Title: List of amphipod families with number of accepted and barcoded species as well as

979 information of the barcoding coverage within family. Families within each category with the

980 highest barcoding coverage indicated in bold.

981

\section{Supplemental file 8}

983 - File format .docx

984 - PRISMA 2020 checklist 


\section{Table 1 (on next page)}

Representation of amphipod families in BOLD.

* in parentheses the number of families without barcoded species but with at least one BIN identified to the genus $(\mathrm{g})$ or family ( $\mathrm{f}$ ) level. 
1 Table 1. Representation of amphipod families in BOLD. * in parentheses the number of families

2 without barcoded species but with at least one BIN identified to the genus (g) or family (f) level.

\begin{tabular}{|l|r|}
\hline Number of families & \\
\hline without any barcoded species & $117(+13 \mathrm{~g}, 5 \mathrm{f})^{*}$ \\
\hline with up to $10 \%$ barcoded species & 47 \\
\hline with $11-20 \%$ barcoded species & 24 \\
\hline with $21-50 \%$ barcoded species & 24 \\
\hline with $>50 \%$ barcoded species & 10 \\
\hline
\end{tabular}

3

4 


\section{Table 2 (on next page)}

Number of amphipod species in each realm with indication of their barcode quality according to grading system from Fontes et al. (2020).

A - consolidated concordance, B - basal concordance, C - multiple BINs for single morphospecies, D - insufficient data; for more detailed explanation of grading system, see Material and methods section. 
1 Table 2. Number of amphipod species in each realm with indication of their barcode quality

2 according to grading system from Fontes et al. (2020). A - consolidated concordance, B - basal

3 concordance, $\mathrm{C}$ - multiple BINs for single morphospecies, D - insufficient data; for more

4 detailed explanation of grading system, see Material and methods section.

\begin{tabular}{|l|c|c|c|c|c|}
\hline & A & B & C & D & all species \\
\hline All species & 100 & 155 & 276 & 468 & 999 \\
\hline Freshwater spp. & 31 & 55 & 140 & 225 & 451 \\
\hline Marine spp. & 58 & 92 & 120 & 226 & 496 \\
\hline Terrestrial spp. & 11 & 8 & 16 & 17 & 52 \\
\hline
\end{tabular}

5

6 


\section{Table 3 (on next page)}

Number of accepted families and species of Amphipoda (according to WAD accessed on 17-07-2020), number of families with representation in BOLD, number of species present in BOLD and mean coverage of barcodes in amphipod families represented in BOLD. 
1 Table 3. Number of accepted families and species of Amphipoda (according to WAD accessed 2 on 17-07-2020), number of families with representation in BOLD, number of species present in 3 BOLD and mean coverage of barcodes in amphipod families represented in BOLD.

\begin{tabular}{|c|c|c|c|c|c|}
\hline & $\begin{array}{c}\text { No. of } \\
\text { families }\end{array}$ & $\begin{array}{c}\text { No. of } \\
\text { species }\end{array}$ & $\begin{array}{c}\text { No. of families } \\
\text { with species } \\
\text { representation } \\
\text { in BOLD }\end{array}$ & $\begin{array}{c}\text { No. of } \\
\text { species } \\
\text { present } \\
\text { in BOLD }\end{array}$ & $\begin{array}{c}\text { Mean barcode coverage } \\
\text { [\%] of those families with } \\
\text { representation in BOLD }\end{array}$ \\
\hline $\begin{array}{c}\text { Very species rich } \\
\text { families (>100 spp.) }\end{array}$ & 33 & 7302 & 32 & 714 & 8 \\
\hline $\begin{array}{c}\text { Species rich families } \\
(31-100 \text { spp.) }\end{array}$ & 30 & 1633 & 22 & 127 & 10 \\
\hline $\begin{array}{c}\text { Moderately species } \\
\text { rich families } \\
(11-30 \text { spp.) }\end{array}$ & 53 & 979 & 26 & 107 & 21 \\
\hline $\begin{array}{c}\text { Low species rich } \\
\text { families (<10 spp.) }\end{array}$ & 123 & 416 & 26 & 51 & 49 \\
\hline
\end{tabular}

4 


\section{Table 4(on next page)}

Percent of families with species belonging to different quality grading categories (Fontes et al., 2020).

A - consolidated concordance, B - basal concordance, C - multiple BINs for single morphospecies, D - insufficient data; for more detailed explanation of grading system, see Material and methods section. 
1 Table 4. Percent of families with species belonging to different quality grading categories

2 (Fontes et al., 2020). A - consolidated concordance, B - basal concordance, C - multiple BINs

3 for single morphospecies, D - insufficient data; for more detailed explanation of grading system,

4 see Material and methods section.

\begin{tabular}{|c|c|c|c|c|c|}
\hline & \multicolumn{5}{|c|}{$\%$ of families } \\
\hline & All families & $\begin{array}{c}\text { Very species } \\
\text { rich families } \\
(>100 \text { spp. })\end{array}$ & $\begin{array}{c}\text { Species rich } \\
\text { families } \\
(31-100 \text { spp. })\end{array}$ & $\begin{array}{c}\text { Moderately species } \\
\text { rich families } \\
(11-30 \text { spp. })\end{array}$ & $\begin{array}{c}\text { Low species } \\
\text { rich families } \\
(<10 \text { spp. })\end{array}$ \\
\hline $\begin{array}{c}\text { At least one sp. in } \\
\text { the category A }\end{array}$ & 32.4 & 65.6 & 31.8 & 16 & 7.7 \\
\hline $\begin{array}{c}\text { At least one sp. in } \\
\text { the category B }\end{array}$ & 31.4 & 28.1 & 36.4 & 28 & 34.6 \\
\hline $\begin{array}{c}\text { At least one sp. in } \\
\text { the category C }\end{array}$ & 10.5 & 0 & 13.6 & 24 & 7.7 \\
\hline $\begin{array}{c}\text { At least one sp. in } \\
\text { the category D }\end{array}$ & 25.7 & 6.3 & 18.2 & 32 & 50 \\
\hline Number of families & 105 & 32 & 22 & 25 & 26 \\
\hline
\end{tabular}

5 
Figure 1

PRISMA 2020 work-flow diagram (Page et al., 2021).

Summary of the data download, identification and screening before analysis. All record removals were done by the leading author of the paper.

\section{Identification, download and screening of BOLD data}

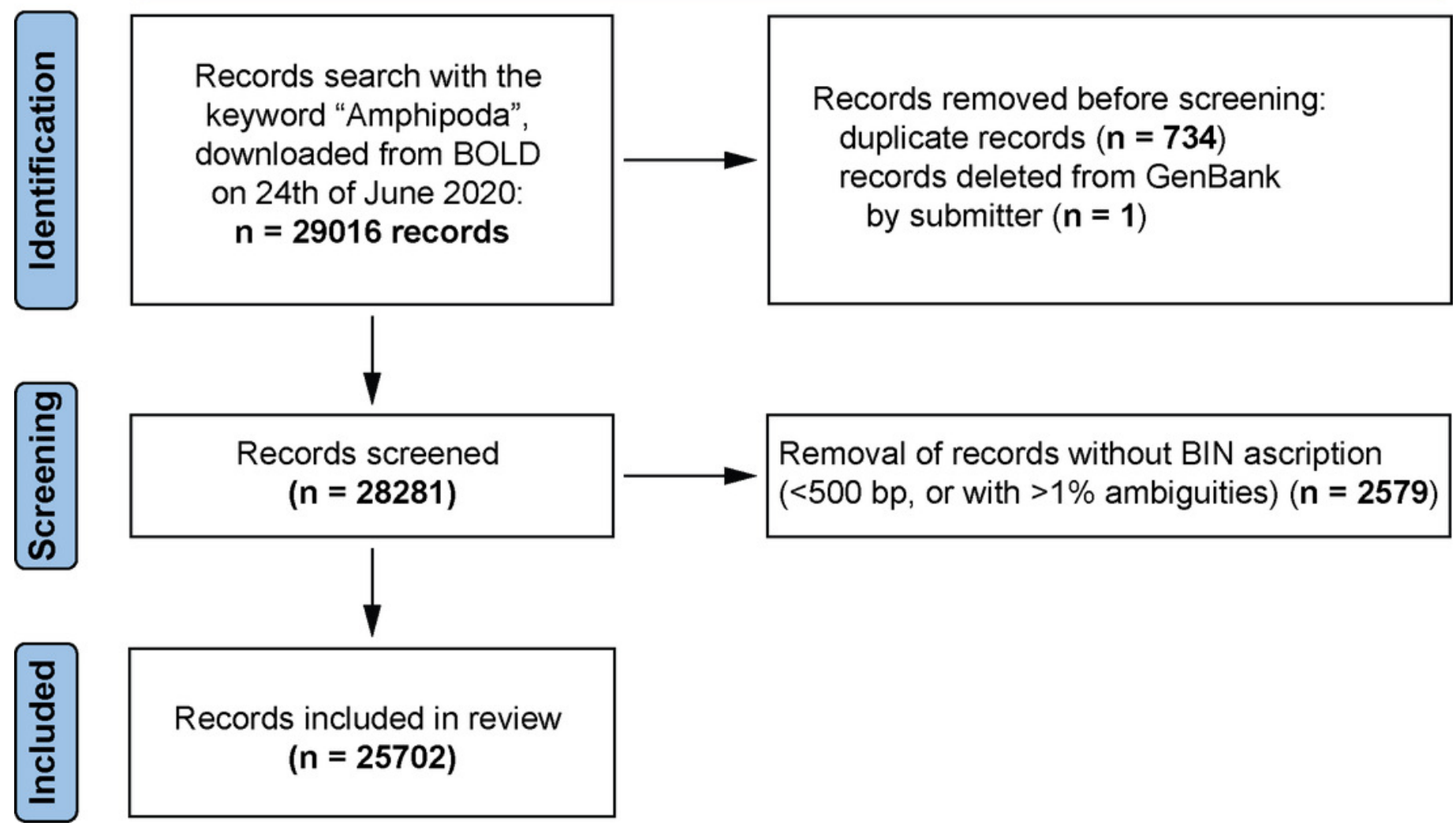




\section{Figure 2}

Environmental origin of the amphipod records (A) and BINs (B) in BOLD database.

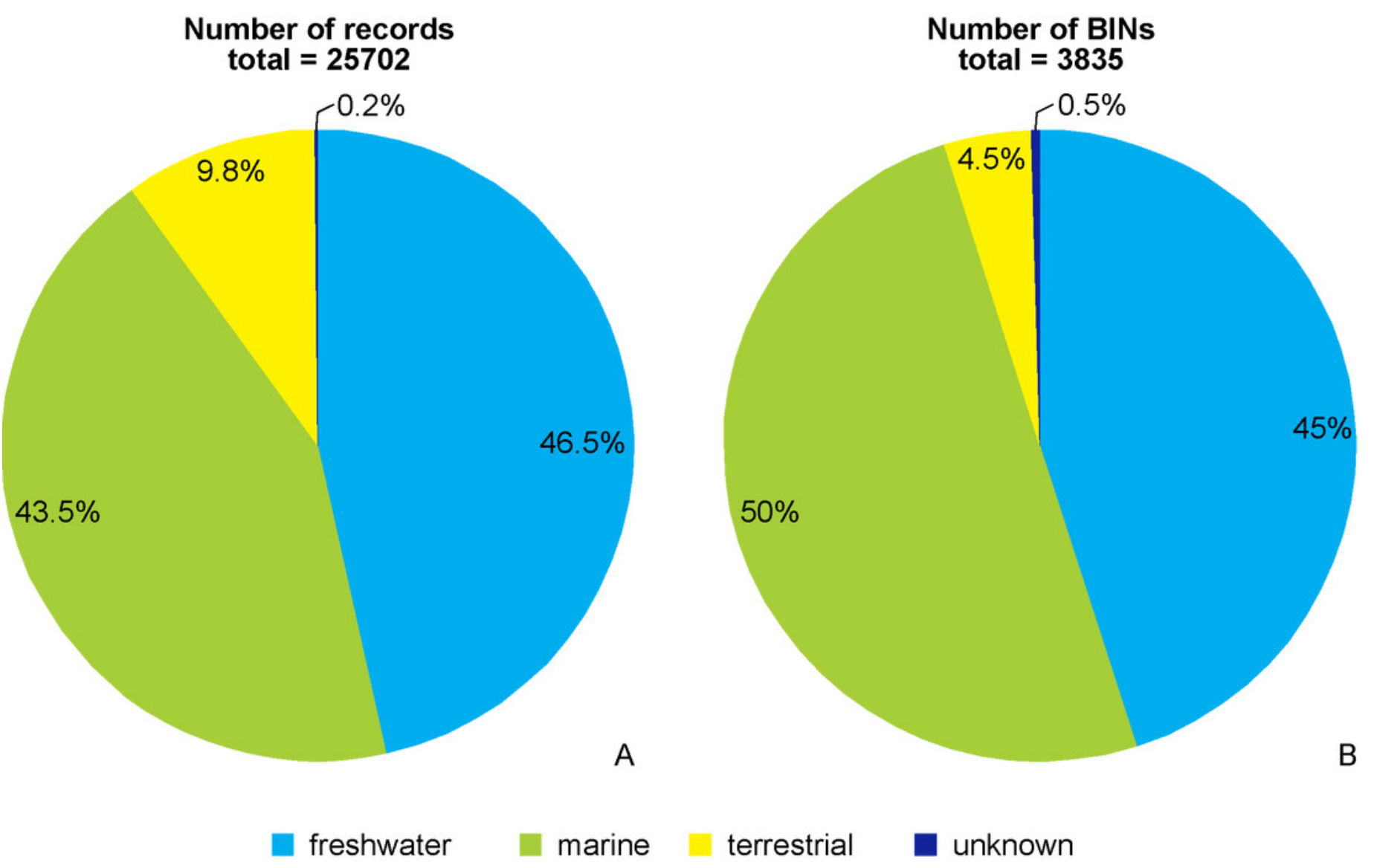


Figure 3

Geographic distribution of amphipod records expressed by sequences present in BOLD (A - freshwater, B - marine, C - terrestrial).

Dots indicate records with exact coordinates, for records without latitude and longitude the country of origin was checked. Background color of the country indicates this number per country. 

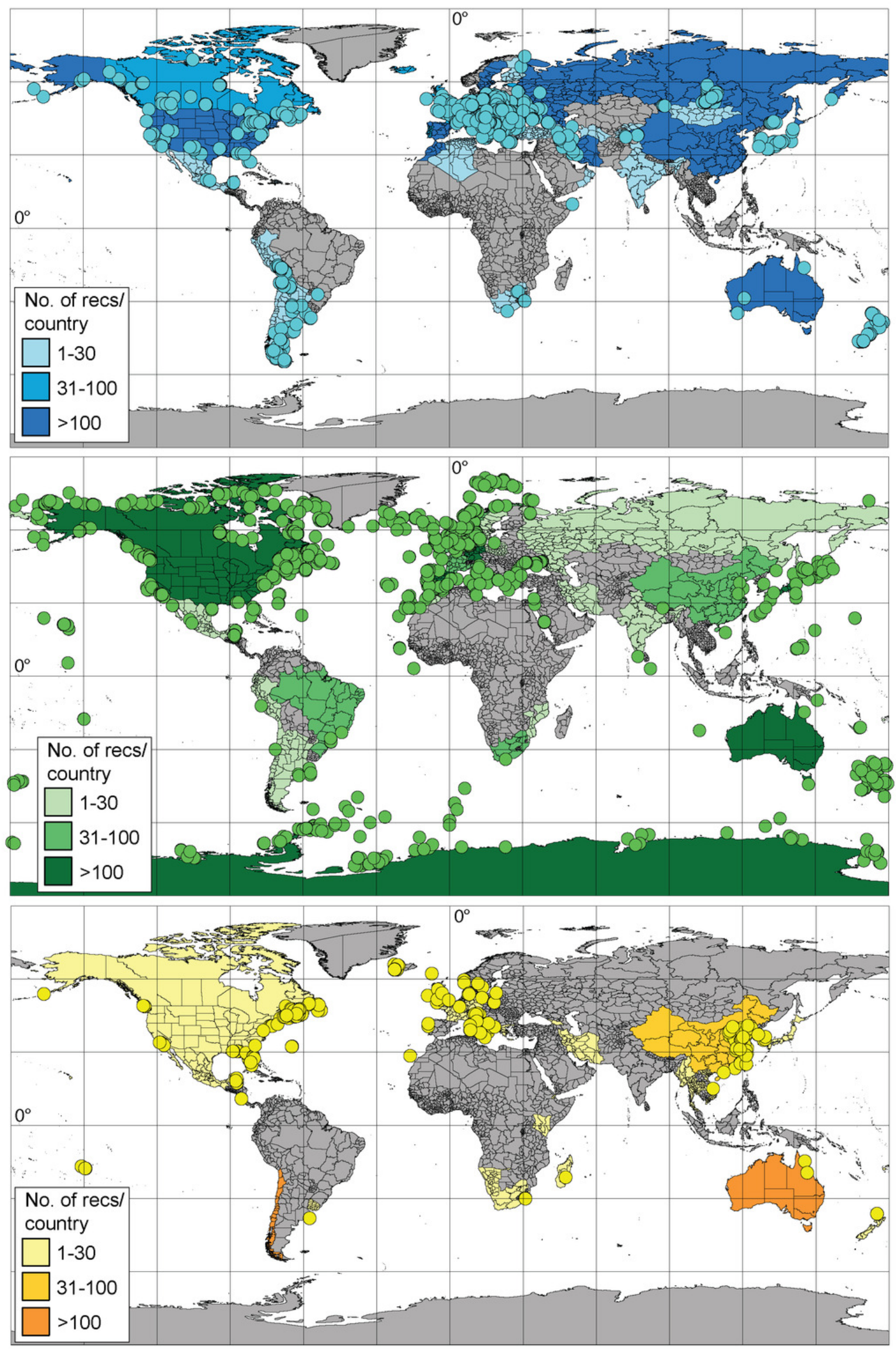

\section{B}


Figure 4

Proportion of records (A) and BINs (B) with different level of identification within freshwater, marine and terrestrial amphipod taxa.
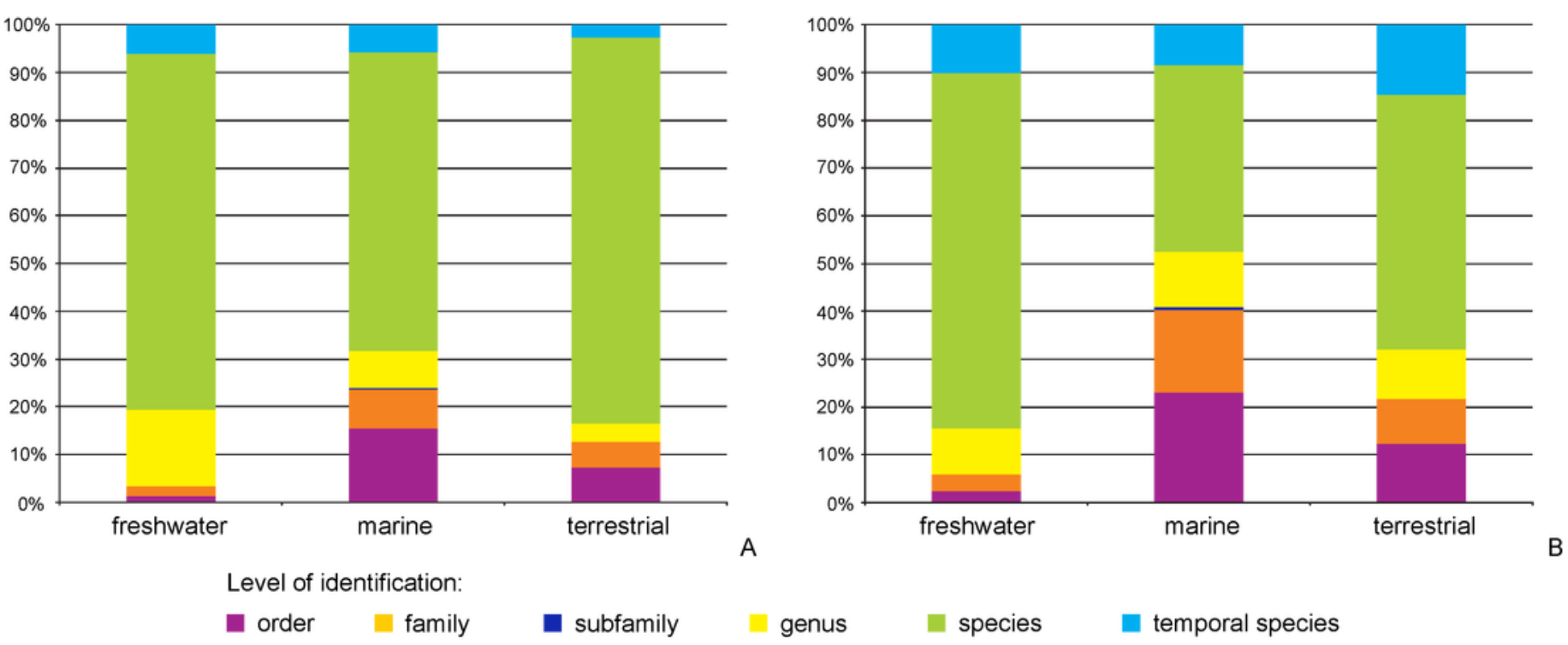


\section{Figure 5}

Number of BINs represented by given number of sequences.

Upper set $(A, B, C)$ - all BINs, lower set $(D, E, F)$ - only BINs with complete species-level identification considered. A, D - freshwater, B, E - marine, C, F - terrestrial taxa.
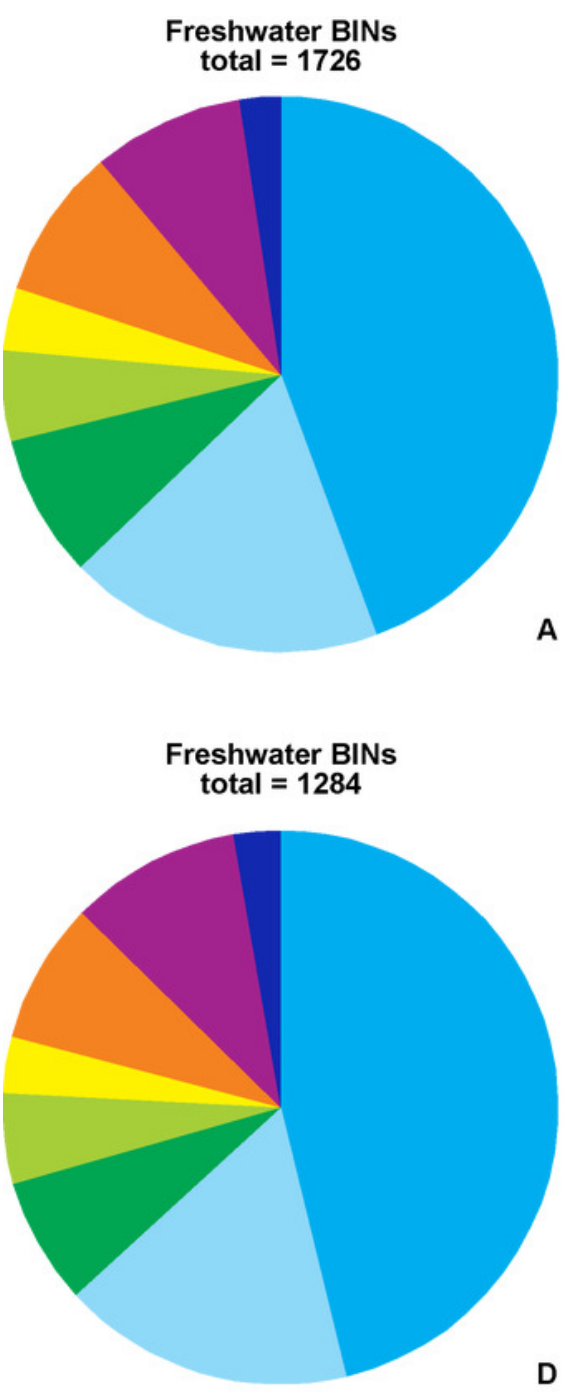
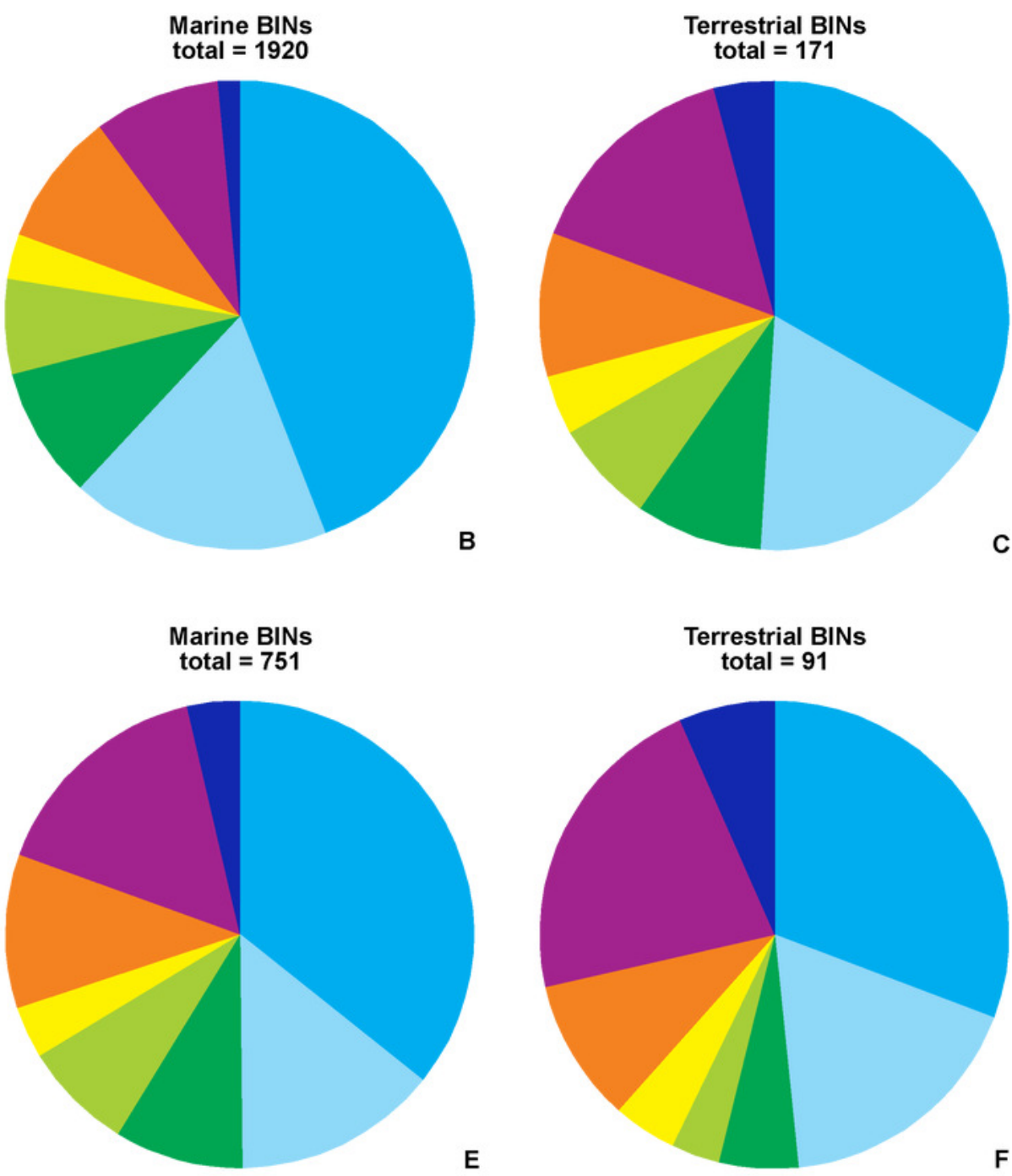

Number of sequences per BIN
만 2
- 3
14
5
$6-10$
$\square 11-50$
$>51$ 
Figure 6

Number of nominal species represented by given number of BINs.

No. of species

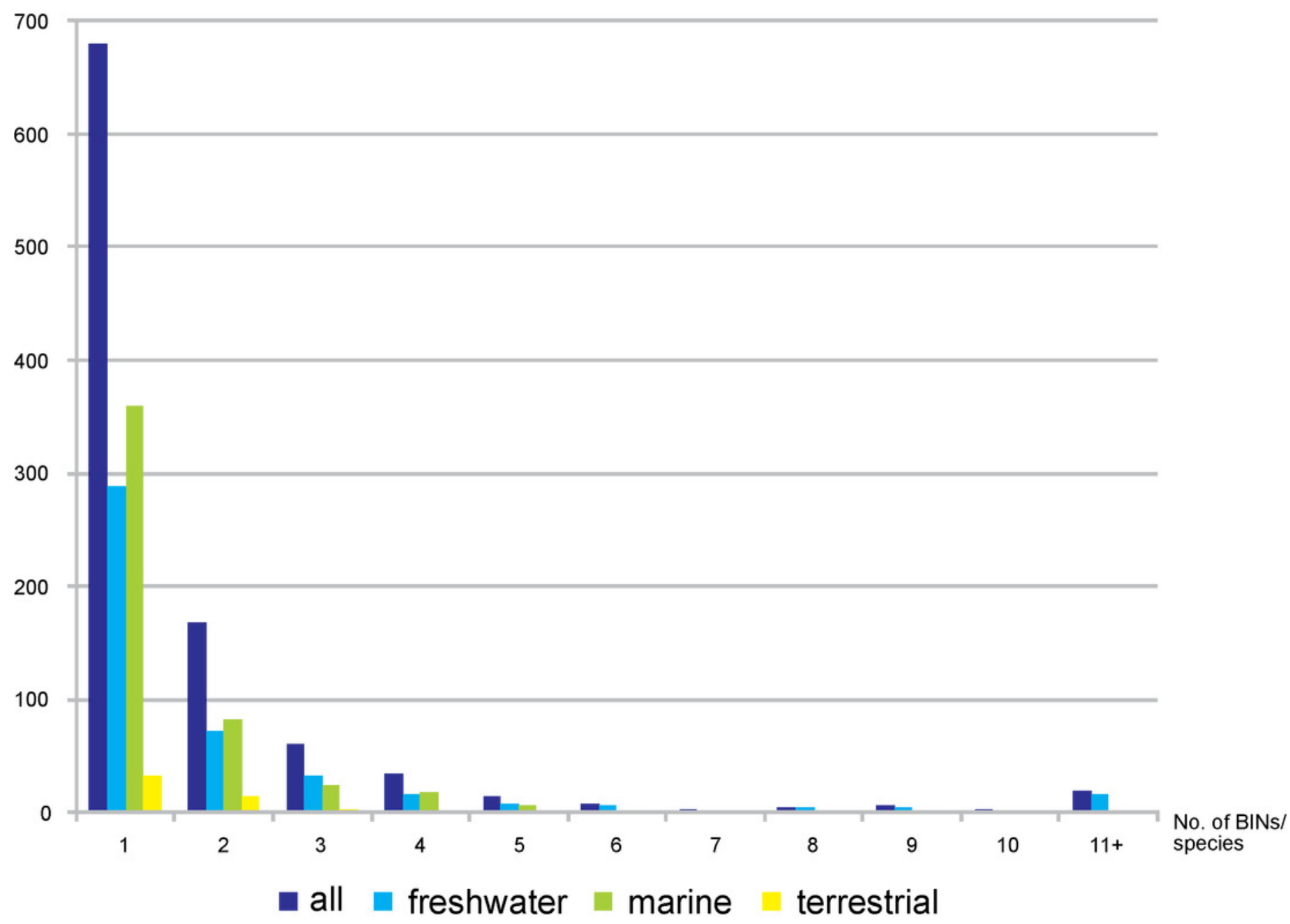

